The Apolipoprotein M/S1P Axis Controls Triglyceride Metabolism and Brown Fat Activity

Christoffersen, Christina; Federspiel, Christine K.; Borup, Anna; Christensen, Pernille M.; Madsen, Andreas N.; Heine, Markus; Nielsen, Carsten H.; Kjaer, Andreas; Holst, Birgitte; Heeren, Joerg; Nielsen, Lars B.

Published in:

Cell Reports

DOI:

10.1016/j.celrep.2017.12.029

Publication date:

2018

Document version

Publisher's PDF, also known as Version of record

Document license:

CC BY-NC-ND

Citation for published version (APA):

Christoffersen, C., Federspiel, C. K., Borup, A., Christensen, P. M., Madsen, A. N., Heine, M., Nielsen, C. H., Kjaer, A., Holst, B., Heeren, J., \& Nielsen, L. B. (2018). The Apolipoprotein M/S1P Axis Controls Triglyceride Metabolism and Brown Fat Activity. Cell Reports, 22(1), 175-188. https://doi.org/10.1016/j.celrep.2017.12.029 


\section{Cell Reports}

\section{The Apolipoprotein M/S1P Axis Controls Triglyceride Metabolism and Brown Fat Activity}

\section{Graphical Abstract}

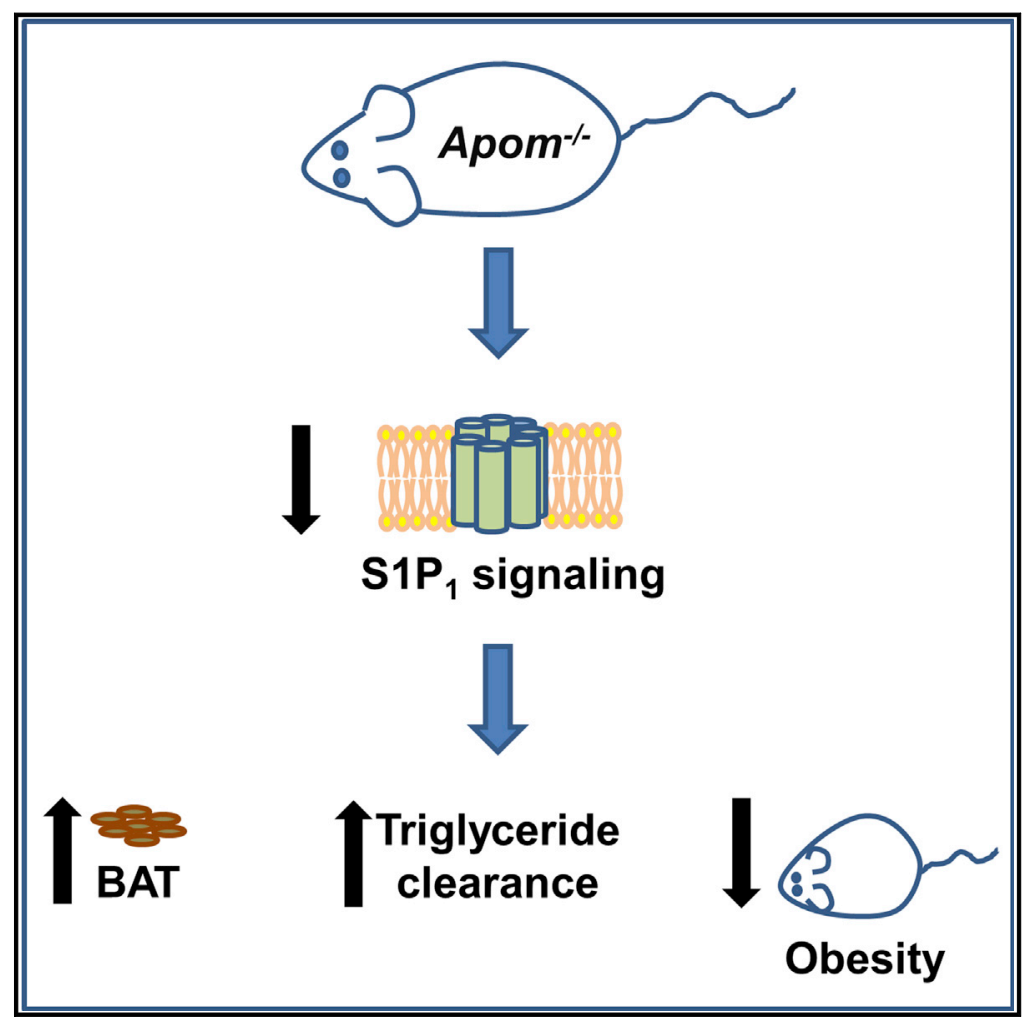

Highlights

- Apolipoprotein M (apoM) deficiency increases the amount of brown adipose tissue

- ApoM deficiency accelerates postprandial triglycerides

- ApoM deficiency protects against diet-induced obesity and improves glucose tolerance

- Decreased sphingosine-1-phosphate stimulation increases brown adipose tissue weight

\section{Authors}

Christina Christoffersen, Christine K. Federspiel, Anna Borup, ..., Birgitte Holst, Joerg Heeren, Lars B. Nielsen

\section{Correspondence}

christina.christoffersen@regionh.dk (C.C.), larsbo@au.dk (L.B.N.)

\section{In Brief}

Apolipoprotein M (apoM) is the carrier of sphingosine-1-phosphate (S1P) in lipoproteins. Christoffersen et al. show that lack of apoM in mice increases the amount of brown adipose tissue, accelerates the turnover of fat, and protects against obesity. The results reveal a link between the apoM/S1P axis and energy metabolism. 


\title{
The Apolipoprotein M/S1P Axis Controls Triglyceride Metabolism and Brown Fat Activity
}

\author{
Christina Christoffersen, ${ }^{1,2,8, *}$ Christine K. Federspiel, ${ }^{1}$ Anna Borup, ${ }^{1,2}$ Pernille M. Christensen, ${ }^{1}$ Andreas N. Madsen,, ${ }^{2,3}$ \\ Markus Heine, ${ }^{6}$ Carsten H. Nielsen, ${ }^{5}$ Andreas Kjaer, ${ }^{5}$ Birgitte Holst, ${ }^{2,3}$ Joerg Heeren, ${ }^{6}$ and Lars B. Nielsen ${ }^{1,2,4,7, *}$ \\ ${ }^{1}$ Department of Clinical Biochemistry, Rigshospitalet, 2100 Copenhagen, Denmark \\ ${ }^{2}$ Department of Biomedical Sciences \\ ${ }^{3}$ Novo Nordisk Center for Basic Metabolic Research \\ ${ }^{4}$ Department of Clinical Medicine \\ University of Copenhagen, 2200 Copenhagen, Denmark \\ ${ }^{5}$ Department of Clinical Physiology, Nuclear Medicine \& PET and Cluster for Molecular Imaging, Rigshospitalet and University of Copenhagen, \\ 2200 Copenhagen, Denmark \\ ${ }^{6}$ Department of Biochemistry and Molecular Cell Biology, Universitätsklinikum Hamburg-Eppendorf, 20246 Hamburg, Germany \\ ${ }^{7}$ Present address: Aarhus University, Aarhus, Denmark \\ ${ }^{8}$ Lead Contact \\ ${ }^{*}$ Correspondence: christina.christoffersen@regionh.dk (C.C.), larsbo@au.dk (L.B.N.) \\ https://doi.org/10.1016/j.celrep.2017.12.029
}

\section{SUMMARY}

Apolipoprotein $M$ (apoM) is the carrier of sphingosine-1-phosphate (S1P) in plasma high-density lipoproteins. S1P is a bioactive lipid interacting with five receptors $\left(\mathrm{S}_{1} \mathrm{P}_{1-5}\right)$. We show that lack of apoM in mice increases the amount of brown adipose tissue (BAT), accelerates the clearance of postprandial triglycerides, and protects against diet-induced obesity (i.e., a phenotype similar to that induced by cold exposure or $\boldsymbol{\beta}_{3}$-adrenergic stimulation). Moreover, the data suggest that the phenotype of apoM-deficient mice is S1P dependent and reflects diminished $\mathrm{S}_{1} \mathrm{P}_{1}$ stimulation. The results reveal a link between the apoM/S1P axis and energy metabolism.

\section{INTRODUCTION}

Excessive caloric intake and insufficient energy expenditure leads to storage of triglycerides in adipose tissues and obesity. Obesity is the prominent cause of insulin resistance and type 2 diabetes in affluent societies (Horton, 1983). Hence, a detailed understanding of processes controlling triglyceride metabolism is warranted to identify new measures to prevent obesity. White adipose tissue (WAT) stores nonutilized energy as triacylglycerols, which can be released as nonesterified fatty acids for energy consumption in metabolically active organs under catabolic conditions. Brown adipose tissue (BAT), characterized by expression of the uncoupling protein 1 (UCP1), uses fatty acids released from intracellular triglyceride stores for $\beta$-oxidation to generate heat by a process known as adaptive thermogenesis (Cannon and Nedergaard, 2004).

Short-term cold exposure increases the activity of BAT and improves insulin sensitivity in patients with type 2 diabetes (Hanssen et al., 2015). BAT also can be activated by the stimulation of the $\beta_{3}$-adrenergic receptors (AdrB3) (Lowell and Flier,
1997). Both cold exposure and treatment with a $\beta_{3}$ agonist (e.g., CL316243) reduce body weight and alleviate diabetes as well as atherosclerosis in rodents (Bartelt et al., 2011; Berbée et al., 2015; Cawthorne et al., 1984; Peirce and Vidal-Puig, 2013; Vallerand et al., 1986). These beneficial effects occur in parallel with increased uptake and metabolism of glucose in BAT. Moreover, activated BAT clears triglyceride-rich lipoproteins from the blood (Bartelt et al., 2011). Triglyceride-rich lipoproteins interact with CD36 and lipoprotein lipase (LPL) on the surface of endothelial cells in BAT (Bartelt et al., 2011). As such, both whole-particle uptake by brown adipocytes and of hydrolyzed triglycerides as free fatty acids (FFAs) are possible pathways for metabolizing triglyceride-rich lipoproteins in BAT (Bartelt et al., 2011; Khedoe et al., 2015).

Sphingosine-1-phosphate (S1P) is a bioactive lipid interacting with 5 different receptors $\left(\mathrm{S}_{1} \mathrm{P}_{1-5}\right)$, mediating effects such as angiogenesis, migration of lymphocytes, and induction of tight junctions between endothelial cells (Camerer et al., 2009; Garcia

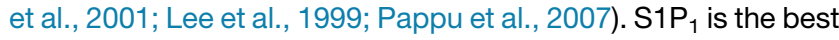
characterized receptor. It plays an important role in maintaining the endothelial barrier (Camerer et al., 2009; Garcia et al., 2001; Liu et al., 2000; Nofer et al., 2004; Paik et al., 2001). The endothelial barrier is compromised in diseases such as multiple sclerosis characterized by migration of lymphocytes across the bloodbrain barrier (Grigoriadis et al., 2015; Prager et al., 2015). Patients with multiple sclerosis benefit from treatment with the S1P analog fingolimod (Kim et al., 2015). Fingolimod also reduces the inflammatory response after transplantation-associated reperfused ischemia in lung tissue and in damaged pancreatic $\beta$ cells of diabetic animal models (Moon et al., 2013; Penaranda et al., 2010; Stone et al., 2015).

High-density lipoproteins (HDLs) protect endothelial cells. HDLs carry more than 40 different apolipoproteins, including apolipoprotein M (apoM) (Davidson et al., 2009). ApoM is a member of the lipocalin superfamily (Christoffersen et al., 2011; Duan et al., 2001) and contains a binding pocket for small lipophilic molecules. As such, apoM is the carrier of Sphingosine-1-phosphate (S1P) in plasma lipoproteins (Christoffersen et al., 2011). 
Approximately $65 \%$ of plasma S1P is bound to apoM in HDLs and $30 \%$ is bound to albumin (Karuna et al., 2011; Murata et al., 2000). ApoM-deficient mice with a lack of HDL-associated S1P display increased vascular permeability in the lungs, suggesting that the apoM/S1P axis is needed to maintain normal vascular barrier function (Christensen et al., 2016; Christoffersen et al., 2011).

Herein, we present data suggesting that an apolipoprotein, apoM, controls BAT activity and that this effect is mediated by an associated sphingolipid, S1P. Also, we show that the apoM/S1P axis has major effects on postprandial triglyceride metabolism and diet-induced obesity. The findings have potential therapeutic implications since we also find that stimulation

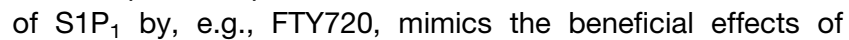
apoM deficiency. Together, the results reveal a link between the apoM/S1P axis and energy metabolism.

\section{RESULTS}

\section{Decreased WAT and Increased BAT in ApoM-Deficient Mice}

$\mathrm{Apom}^{-1-}$ mice have reduced body weight (Figure S1A). To explore this finding, we assessed the lean and adipose tissue masses of female mice housed at $23^{\circ} \mathrm{C}$. On MRI, the fat mass (Figure 1A), but not the lean mass (Figure S1B), was lower in $\mathrm{Apom}^{-1-}$ than in wild-type mice. Upon postmortem dissection, the weight of the intra-abdominal epididymal WAT (epiWAT) was reduced by $\sim 60 \%$ (Figure $1 \mathrm{~B}$ ), whereas the weight of both interscapular (IsBAT) and subscapular (SubBAT) BAT (Figure 1C) was increased in $\mathrm{Apom}^{-1-}$ compared to wild-type mice. On positron emission tomography-computed tomography (PET-CT) scanning using ${ }^{18} \mathrm{~F}$-flurodeoxyglucose (FDG), the FDG uptake by BAT tended to be higher in Apom $^{-1-}$ mice than in wild-type mice (Figures 1D and 1E). These findings suggest that apoM deficiency results in decreased deposition of fat in WAT, possibly as a result of increased BAT activity.

Next, we compared structural and biochemical characteristics of BAT in $\mathrm{Apom}^{-1-}$ mice and wild-type mice housed at $23^{\circ} \mathrm{C}$. BAT is characterized by a high content of the mitochondria-membrane lipid cardiolipin and of the uncoupling protein 1 (UCP1) (Faber et al., 2014; Golozoubova et al., 2001; Lee et al., 2015). Both cardiolipin (Figure 2A) and UCP1 (Figure 2B; Figure S2) were more abundant in BAT from $\mathrm{Apom}^{-1-}$ mice than from wild-type mice. On histological examination, Apom $^{-1-}$ mice had more but smaller lipid droplets in BAT than did wild-type mice (Figures 2C-E). Also, the mRNA expression of the glucose transporter GLUT4 and AdrB3 was increased, whereas mRNA expression of peroxisome proliferator-activated receptor gamma coactivator 1- $\alpha$ (PGC-1 $\alpha$ ), a transcriptional co-regulator of various genes involved in energy metabolism) was decreased in BAT from $\mathrm{Apom}^{-1-}$ mice as compared to wild-type mice (Figure 2F). Combined, these data suggest that apoM deficiency increases the metabolic activity of BAT. Notably, in WAT, the expression of LPL, CD36, and GLUT4 mRNA were increased in $\mathrm{Apom}^{-1-}$ mice compared to wild-type mice (Figure 2F).

\section{Abrogated Response of BAT to Cold Exposure or} $\beta_{3}$-Adrenergic Stimulation in Apom $^{-1-}$ mice BAT activity in wild-type mice can be increased by cold exposure (Cannon and Nedergaard, 2004; Lowell and Flier, 1997).
Accordingly, in wild-type mice kept at $4^{\circ} \mathrm{C}$ for 6 days, the weight of BAT was increased and that of WAT was decreased (Figure $3 \mathrm{~A}$ ) compared to wild-type mice kept at $23^{\circ} \mathrm{C}$ (Figures $1 \mathrm{~B}$ and 1C). In contrast, in Apom $^{-1-}$ mice, BAT and WAT weights were not affected by cold exposure. Hence, Apom $^{-1-}$ and wild-type mice had similar BAT and WAT weights when housed at $4^{\circ} \mathrm{C}$ (Figure $3 \mathrm{~A}$ ). Also, at $4^{\circ} \mathrm{C}$, the number (Figure 3B) and size (Figure $3 \mathrm{C}$ ) of lipid droplets, as well as the contents of UCP1 protein (Figure 3D and S2) and cardiolipin (Figure 3E) in BAT, were similar in $\mathrm{Apom}^{-1-}$ and wild-type mice. Moreover, the effects of apoM deficiency on BAT and WAT mRNA expression were markedly dampened or abrogated in mice kept at $4^{\circ} \mathrm{C}$ (Figure $3 \mathrm{~F}$ ). To explore whether the acute response to cold also was abrogated, BAT weight was measured in $\mathrm{Apom}^{-1}$ and wild-type mice that had been kept at $4^{\circ} \mathrm{C}$ for $16 \mathrm{hr}$. Under these conditions wild-type mice had an increased mass of BAT compared to mice kept at $23^{\circ} \mathrm{C}$, but the difference was less pronounced than after 6 days of housing (Figures 1C, 3A, and 3G). After $16 \mathrm{hr}$ at $4^{\circ} \mathrm{C}, \mathrm{Apom}^{-1-}$ mice had less BAT mass than wildtype mice and similar BAT mass compared to $\mathrm{Apom}^{-1-}$ mice housed at $23^{\circ} \mathrm{C}$ or $4^{\circ} \mathrm{C}$ for 6 days (Figures 1C, 3A, and 3G).

Like cold exposure, treatment with the adrenergic $\beta_{3}$-receptor agonist CL316243 (Lowell and Flier, 1997) increased BAT and decreased WAT weights in wild-type mice housed at $23^{\circ} \mathrm{C}$ (Figure $3 \mathrm{H})$. CL316243 also increased BAT volume as assessed with PET-CT (Figure 1E). As for cold exposure, these effects of CL316243 were absent in $\mathrm{Apom}^{-/-}$mice (Figures 1E and $3 \mathrm{H}$ ).

\section{Increased Uptake of Triglycerides in BAT of Apom ${ }^{-/-}$ Mice}

Upon cold exposure or nergic $\beta_{3}$-receptor stimulation, activated BAT becomes a major tissue site for the clearance of plasma triglycerides from the circulation (Bartelt et al., 2011). We assessed whether the increased BAT in $\mathrm{Apom}^{-1-}$ mice kept at $23^{\circ} \mathrm{C}$ likewise accelerates triglyceride metabolism. Remarkably, upon intragastric administration of a bolus of olive oil, the pronounced increase of the plasma triglyceride concentration seen in wild-type mice was almost absent in $\mathrm{Apom}^{-1-}$ mice (Figure 4A). Also, fasting plasma triglyceride concentrations were $\sim 30 \%$ lower in $\mathrm{Apom}^{-1-}$ mice than in wild-type mice (Christoffersen et al., 2008). LPL plays a key role in peripheral removal of plasma triglycerides by lipolysis (Williams and Fisher, 2011). The plasma LPL activity after the injection of heparin was increased in $\mathrm{Apom}^{-/-}$mice compared to wild-type mice (Figure 4B). Moreover, when lipolysis was blocked with Triton WR-1339, the plasma triglyceride concentration increased at the same rate in fasting $\mathrm{Apom}^{-/-}$mice and wild-type mice (Figure 4C). Hence, the reduced plasma triglyceride concentrations in $\mathrm{Apom}^{-1-}$ mice likely reflect increased peripheral clearance involving LPL.

To examine the metabolic fate of the postprandial plasma triglycerides, olive oil was administered intragastrically together with ${ }^{3} \mathrm{H}$-triolein. ${ }^{3} \mathrm{H}$-triolein uptake was markedly increased in the IsBAT of $\mathrm{Apom}^{-1-}$ mice compared with wild-type mice (Figure 4D). Also, double-labeled ${ }^{3} \mathrm{H}$-cholesterylhexadecylether and ${ }^{14} \mathrm{C}$-triolein chylomicron-like particles were injected intravenously to assess whole-particle uptake by tissues (Figures $4 \mathrm{E}$ and $4 \mathrm{~F}$ ). The uptake of the double-labeled particles was increased both in BAT and WAT of $\mathrm{Apom}^{-1-}$ mice compared 
A

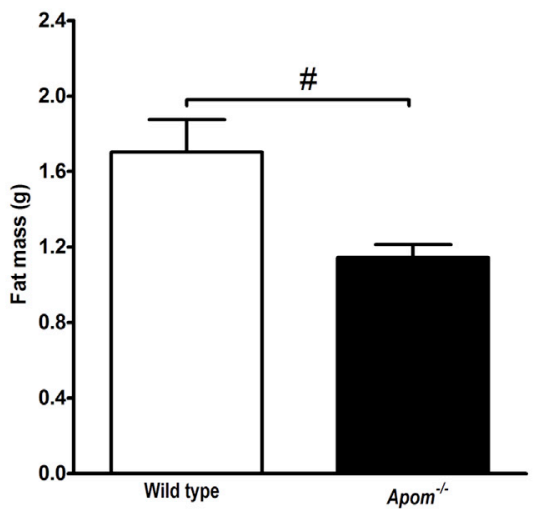

C

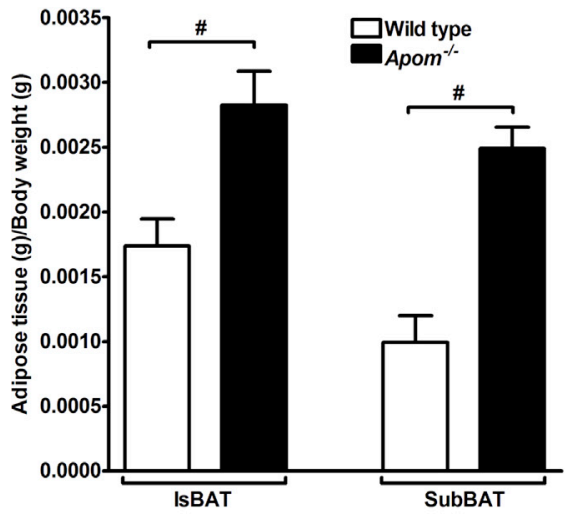

E

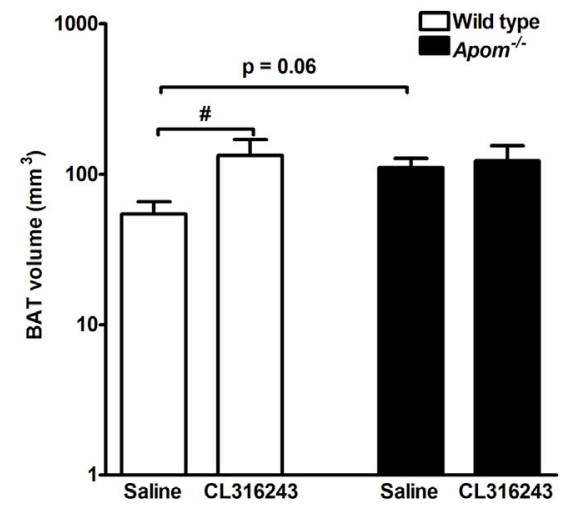

B

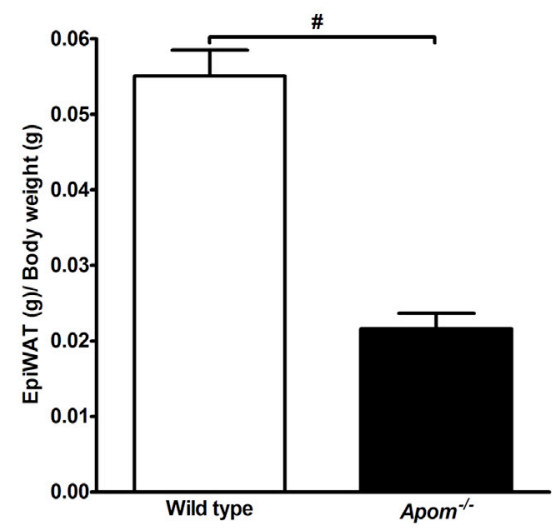

D

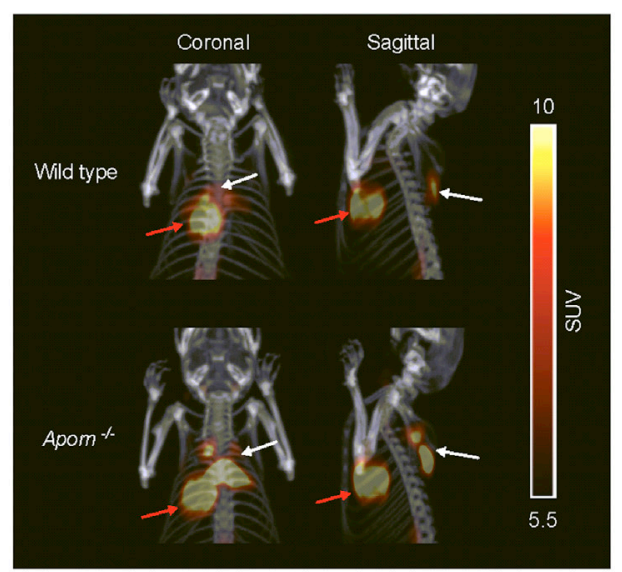

Figure 1. Apolipoprotein M Affects the Mass of WAT and BAT at $23^{\circ} \mathrm{C}$

(A) Mass of fat analyzed by EchoMRI scanning of $\operatorname{Apom}^{-1-}(n=7)$ and wild-type mice $(n=6)$.

(B and C) Mass of epiWAT (B) and BAT, including IsBAT and SubBAT (C) in wild-type $(n=6)$ mice and Apom ${ }^{-1-}(n=7)$ mice.

(D) Representative PET-CT images from animals housed at $23^{\circ} \mathrm{C}$. White and red arrows indicate FDG uptake in BAT and heart, respectively.

(E) BAT volume measured by PET-CT scanning in mice $(n=4)$ receiving either saline or $\beta_{3}$ agonist CL316243 subcutaneously before FDG.

Error bars represent SEM. \#p $<0.05$ analyzed by Student $t$ test. See also Figure $\mathrm{S} 1$.

to wild-type mice. Interestingly, the $\mathrm{Apom}^{-1-}$ mice in parallel displayed a reduced uptake of the double-labeled whole lipoprotein particles in the heart, possibly reflecting a shift in energy utilization. These data reveal that apoM deficiency increases the uptake of plasma triglycerides in BAT.
Protection against Diet-Induced Obesity in $\mathrm{Apom}^{-/-}$ Mice

Activated BAT protects against diet-induced obesity (Cawthorne et al., 1984; Peirce and Vidal-Puig, 2013; Vallerand et al., 1986). We, therefore, hypothesized that $\mathrm{Apom}^{-1-}$ mice would 
A

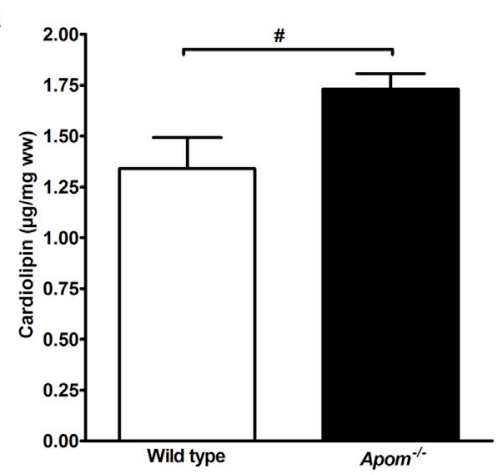

C

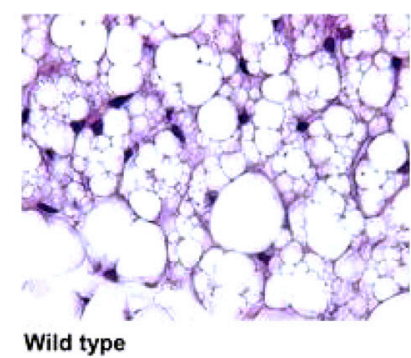

D

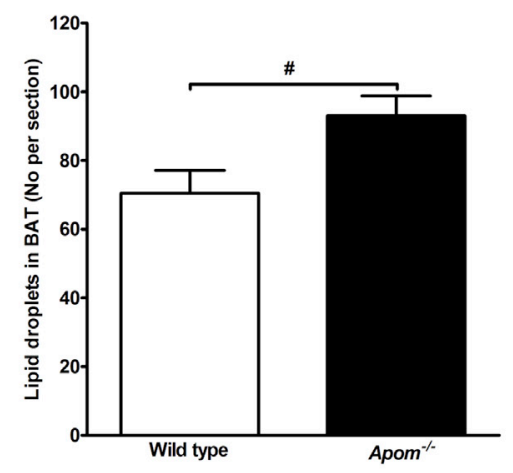

$\mathbf{F}$

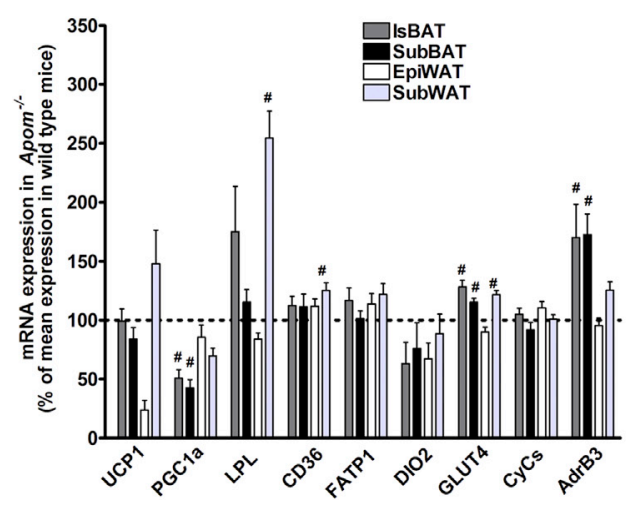

B

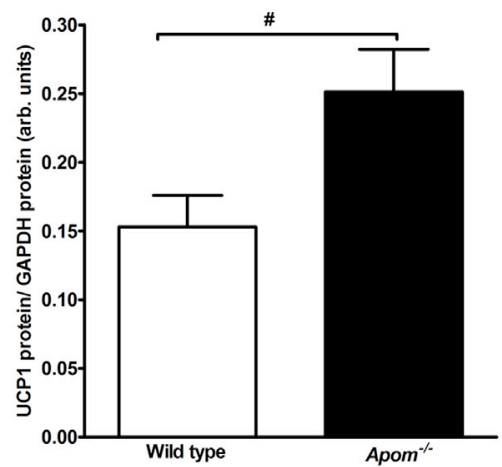

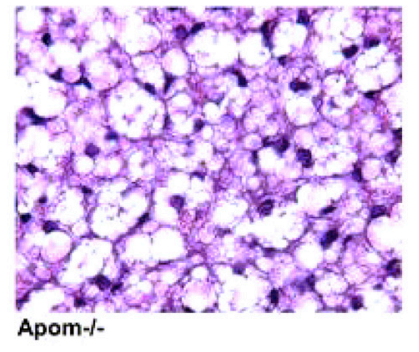

E

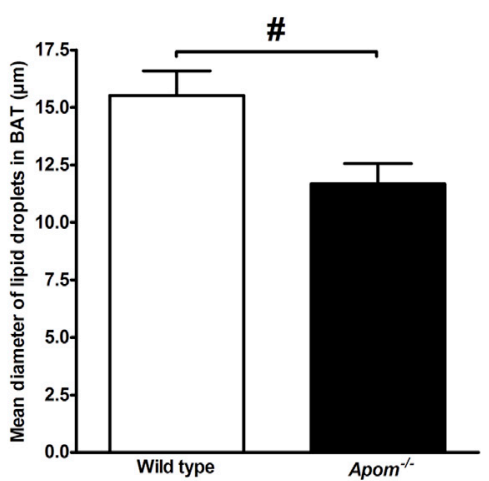

(legend on next page) 
be resistant to obesity when fed a high-fat diet. Indeed, feeding a diet containing $60 \%$ fat for 10 weeks resulted in lower body weight $(28.4 \pm 1.2 \mathrm{~g}$ versus $33.9 \pm 1.1 \mathrm{~g}, \mathrm{p}<0.01)$ in $\mathrm{Apom}^{-1-}$ mice than in wild-type mice (Figure S3A). Accordingly, glucose tolerance tests were improved in $\mathrm{Apom}^{-1-}$ mice compared to wild-type mice after 10 weeks of being fed a high-fat diet (Figures $4 \mathrm{G}$ and $4 \mathrm{H})$.

To examine the effect of apoM on energy utilization, lean mice were placed in metabolic cages. At $23^{\circ} \mathrm{C}$ there were no differences between $\mathrm{Apom}^{-/-}$mice and wild-type mice in food or water intake or energy consumption. Increased energy consumption was observed upon refeeding after $24 \mathrm{hr}$ of fasting at $23^{\circ} \mathrm{C}$. Here, the respiratory exchange rate (RER) was reduced in $\mathrm{Apom}^{-1-}$ mice, indicating a higher utilization of fat (compared to carbohydrate) than that in wild-type mice (Table 1), which may be a result of the slightly lower food intake observed in these mice. At $23^{\circ} \mathrm{C}$ the animals also were fed a high-fat diet after $12 \mathrm{hr}$ of fasting (Table S1). On a high-fat diet, the $\mathrm{Apom}^{-1-}$ mice had reduced food intake and a tendency toward reduced calorie consumption compared to wild-type mice. The RER levels were similar in $\mathrm{Apom}^{-1-}$ mice and wild-type mice.

Spuriously, the core body temperature of the $\mathrm{Apom}^{-/-}$mice was slightly lower than in the wild-type mice at $4^{\circ} \mathrm{C}, 23^{\circ} \mathrm{C}$, and $30^{\circ} \mathrm{C}$ (Table 1). The latter finding could reflect increased heat loss, either via the tail or from the body surface, because the temperature was higher in $\mathrm{Apom}^{-/-}$mice than in wild-type mice when recorded with an infrared camera (Figures S3B-S3E).

To test the effect of acute cold on body temperature and metabolic activity, animals were examined during $16 \mathrm{hr}$ of acute exposure to $4^{\circ} \mathrm{C}$. The core body temperature significantly dropped in $\mathrm{Apom}^{-1-}$ mice compared to wild-type mice (Figure S4). Likewise, after $12 \mathrm{hr}$ of exposure to $4^{\circ} \mathrm{C}$, the RER was reduced in $\mathrm{Apom}^{-/-}$mice compared to wild-type mice without any significant change in food intake, water intake, or activity.

\section{BAT Activation Mediated by Decreased S1P $_{1}$ Receptor Stimulation}

Because apoM is the physiological carrier of S1P (Christoffersen et al., 2011), the effects of apoM deficiency on BAT could be mediated by altered stimulation of S1P receptors. Therefore, the cellular distribution of $\mathrm{S}_{1} \mathrm{P}_{1}$ and $\mathrm{S}_{1} \mathrm{P}_{3-5}$ receptor mRNA in BAT and WAT was analyzed after fluorescenceactivated cell (FACS) sorting of endothelial cells (CD31 ${ }^{+}$cells), macrophages $\left(\mathrm{CD} 11^{+}\right.$cells), and adipocytes (flow-through) (Figure S5). S1P 1 mRNA was expressed mainly in the endothelial cells (Figure S5A), whereas $\mathrm{S}_{1} \mathrm{P}_{3} \mathrm{mRNA}$ was seen mainly in

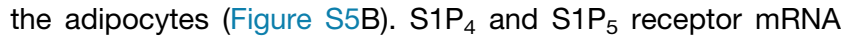

expressions were below the detection limit of the RT-PCR assays.

FTY720 (i.e., Fingolimod) is an S1P analog used in the treatment of patients with multiple sclerosis (Kim et al., 2015). In mice, FTY720 $(0.5 \mathrm{mg} / \mathrm{kg})$ works as a functional $\mathrm{S}_{1} \mathrm{P}_{1}$ receptor antagonist, but it also can interact with $\mathrm{S} \mathrm{P}_{3-5}$ (Brinkmann et al., 2002; Mandala et al., 2002). When administered to wild-type mice, FTY720 $(0.5 \mathrm{mg} / \mathrm{kg})$ increased IsBAT weight (Figure 5A). This effect was absent in the Apom $^{-/-}$mice, implying that the increased weight of BAT in apoM deficiency is S1P dependent.

To further address the putative involvement of $\mathrm{S}_{1} \mathrm{P}_{1}$ receptors in BAT formation, wild-type mice and $\mathrm{Apom}^{-1-}$ mice were treated with an $\mathrm{S}_{1} \mathrm{P}_{1}$ receptor antagonist $(\mathrm{W} 146)$ or an $\mathrm{S}_{1} \mathrm{P}_{1}$ re-

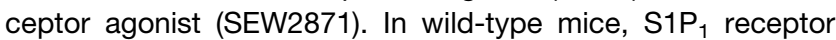
antagonism with W146 increased BAT weight, whereas $\mathrm{S}_{1} \mathrm{P}_{1}$ agonism with SEW2871 had no effect on BAT weight. In Apom ${ }^{-/-}$ mice, $\mathrm{S} 1 \mathrm{P}_{1}$ receptor agonism with SEW2871 decreased BAT weight, and $\mathrm{S}_{1} \mathrm{P}_{1}$ receptor antagonism with $\mathrm{W} 146$ had no effect (Figure 5B). BAT weight was not affected when $\mathrm{Apom}^{-1-}$ mice and wild-type mice were treated with either an $\mathrm{S}_{1} \mathrm{P}_{3}$ receptor antagonist (Bml-241) or an agonist (Cym-5541) (data not shown). Together, these results imply that inhibition of the $\mathrm{S}_{1} \mathrm{P}_{1}$ receptor increases BAT formation.

To explore whether diminished stimulation of the $\mathrm{S}_{1} \mathrm{P}_{1}$ receptor per se could induce browning of adipocytes, pre-adipocytes were differentiated into beige adipocytes in the presence of HDL-apoM, HDL+apoM, S1P, SEW2871, FTY720, or W146. The UCP1 mRNA expression increased when cells were exposed to HDL-apoM, FTY720, or W146. In contrast HDL+apoM, SEW2871, and S1P tended to reduce UCP1 mRNA expression (Figure $5 \mathrm{C}$ ). The in vivo biology is, however, more complex, as to why analysis of cultured adipocytes may not be sufficient to mimic an interplay between surrounding cell types such as endothelial cells expressing $\mathrm{S}_{1} \mathrm{P}_{1}$ and adipocytes.

$\mathrm{S}_{1} \mathrm{P}_{1}$ receptor mRNA was confined mainly to endothelial cells (Figure $\mathrm{S} 5 \mathrm{~A}$ ). The $\mathrm{S}_{1} \mathrm{P}_{1}$ receptors are central to controlling endothelial permeability in the lungs (Christensen et al., 2016). Therefore, we examined the effect of FTY720 and apoM on the BAT endothelial permeability, as judged by the uptake of Evans Blue after intravenous injection. The $\mathrm{Apom}^{-1-}$ mice had markedly increased Evans Blue uptake in BAT as compared to the wild-type mice. In the wild-type mice, administration of FTY720 increased Evans Blue uptake in BAT (Figure 5D) and completely eliminated the difference in BAT Evans Blue uptake between wild-type mice and $\mathrm{Apom}^{-1-}$ mice (Figure 5D). Hence, the data suggest that apoM preserves the endothelial permeability of $\mathrm{BAT}$ in an $\mathrm{S}_{1} \mathrm{P}_{1}$ receptor-dependent manner.

Figure 2. Apolipoprotein M Affects BAT Morphology and mRNA Expression in Mice Housed at $23^{\circ} \mathrm{C}$

(A) Cardiolipin expressed per milligram tissue wet weight of BAT from wild-type $(n=7)$ mice and Apom ${ }^{-1-}(n=8)$ mice.

(B) UCP1 in protein extracts from BAT in Apom $^{-1-}(n=5)$ mice and wild-type mice $(n=4)$. UCP1 levels were normalized with GAPDH and analyzed against a standard curve using $5,10,30,50$, and $70 \mu \mathrm{g}$ total proteins.

(C) HE-stained sections of BAT.

(D and E) Numbers (D) and diameter (E) of lipid droplets in BAT from HE-stained sections from 4 Apom $^{-1-}$ and wild-type mice.

(F) mRNA expression in Apom ${ }^{-1-}$ mice $(n=8)$ calculated as percentage of the mean expression in wild-type mice $(n=7)$.

FATP1, fatty acid transporter protein 1; DIO2, deiodinase iodothyronine type 2; CyCs, cytochrome c. Error bars represent SEM. \#p < 0.05 analyzed by Student's $t$ test. See also Figure S2. 
A

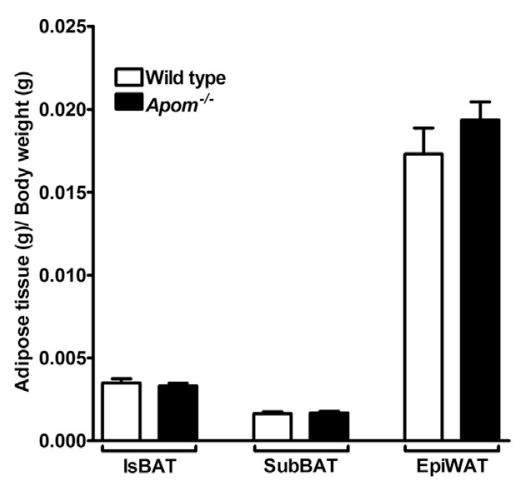

C

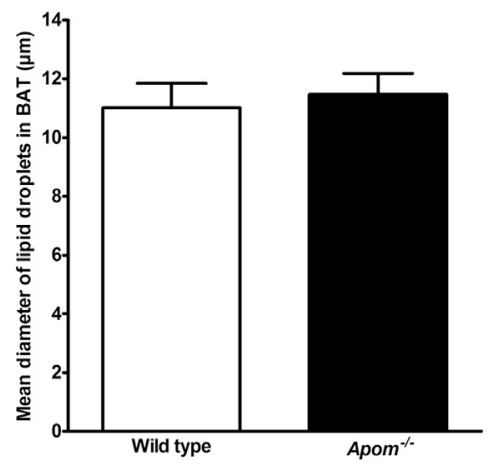

E

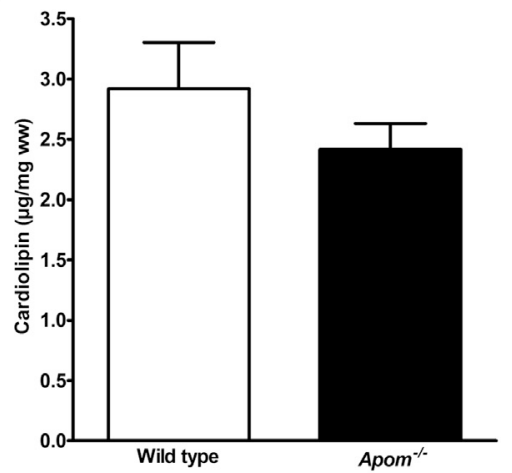

G

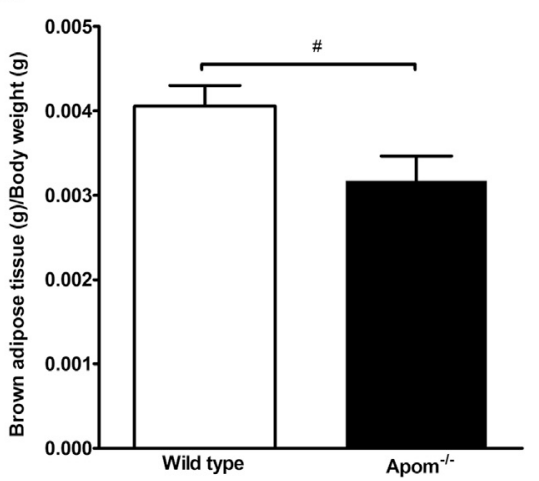

B

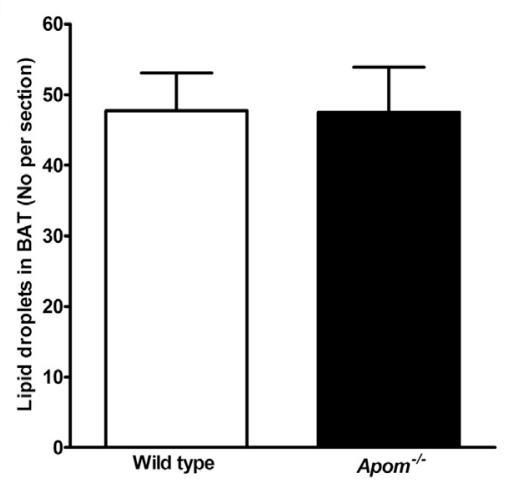

D

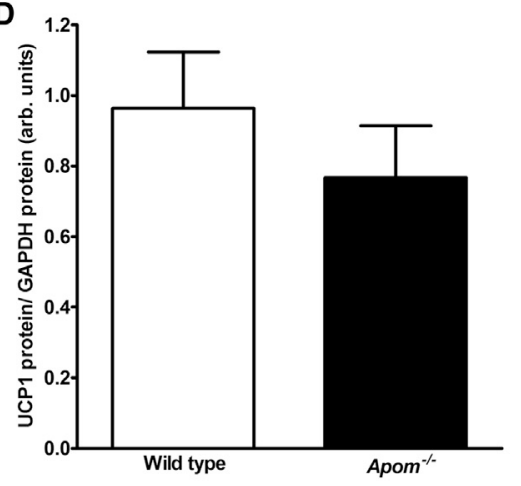

F

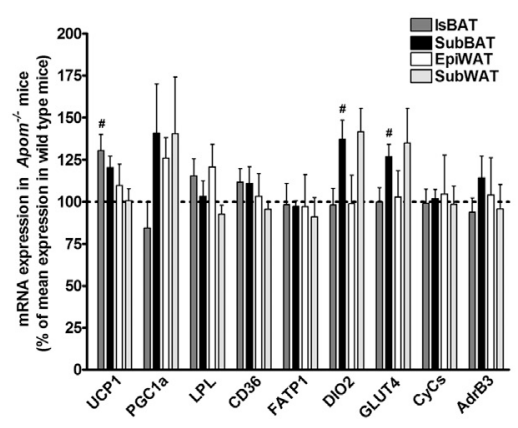

H

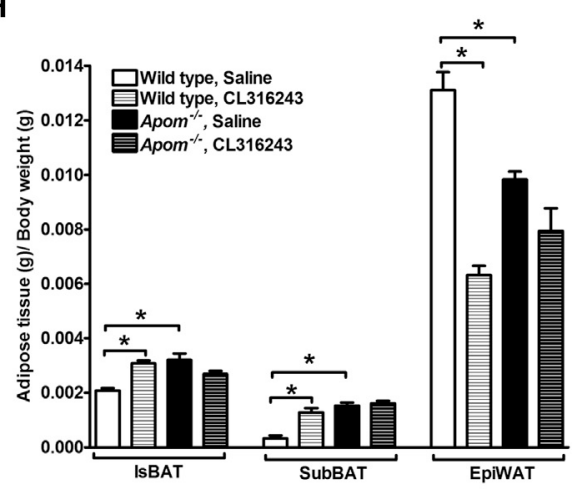


Increased Triglyceride Metabolism in Apom ${ }^{-/-}$Mice Is S1P Dependent

Because the infrared recordings suggested that the $\mathrm{Apom}^{-1-}$ mice lose heat from the tail at $23^{\circ} \mathrm{C}$ (Figures S3B and S3C), it was conceivable the increased BAT formation in $\mathrm{Apom}^{-/-}$ mice could be affected by the, albeit rather modest, reduction of core body temperature. We, therefore, housed mice at $30^{\circ} \mathrm{C}$. At this temperature, the heat loss from the tail was similar in $\mathrm{Apom}^{-1-}$ mice and wild-type mice (Figure S6). In accordance with previous studies of mice kept at $28^{\circ} \mathrm{C}-30^{\circ} \mathrm{C}$ (Wu et al., 2011), BAT uptake of FDG was not detectable on PET-CT either in $\mathrm{Apom}^{-1-}$ mice or in wild-type mice, unless stimulated with CL316243 (Figure 5E). Nevertheless, upon intragastric administration of a bolus of olive oil, the plasma triglyceride concentration still increased less in $\mathrm{Apom}^{-1-}$ mice than in wild-type mice (Figure 5F), suggesting that the effect of apoM deficiency on plasma triglyceride catabolism is not secondary to heat lossinduced BAT formation. FTY720-treated mice were furthermore subjected to an intragastric bolus of olive oil and ${ }^{3} \mathrm{H}$-triolein. In wild-type mice, FTY720 diminished the olive oil-induced increase of plasma triglycerides (Figure $5 \mathrm{G}$ ) and increased the uptake of ${ }^{3} \mathrm{H}$-triolein in BAT (Figure $5 \mathrm{H}$ ). These effects of FTY720 were not present in $\mathrm{Apom}^{-1-}$ mice. This further supports the notion that the effect of apoM deficiency on plasma triglyceride removal in BAT is mediated directly via the S1P system.

\section{DISCUSSION}

The present results demonstrate a link between the apoM/S1P axis, BAT, and triglyceride metabolism. We show that the lack of apoM in mice increases the amount of BAT, accelerates the clearance of postprandial triglycerides, protects against dietinduced obesity, and improves glucose tolerance, i.e., a phenotype similar to that induced by cold exposure or $\beta_{3}$-adrenergic stimulation (Bartelt et al., 2011). Moreover, the data suggest that the phenotype of apoM-deficient mice is S1P dependent and reflect diminished $\mathrm{S}_{1} \mathrm{P}_{1}$ receptor stimulation.

The results imply that the apoM/S1P axis directly affects endothelial function in BAT in an $\mathrm{S}_{1} \mathrm{P}_{1}$-dependent manner because $\mathrm{S}_{1} \mathrm{P}_{1}$ receptor mRNA was robustly expressed in the BAT endothelial cell fraction and because the $\mathrm{Apom}^{-1-}$ mice displayed increased BAT endothelial permeability. Also, FTY720-treated wild-type mice had increased BAT endothelial permeability and turnover of triglycerides compared to untreated wild-type mice.
Increased vascular permeability after FTY720 stimulation in wild-type mice also has been observed in lung tissue (Oo et al., 2011). It is unknown whether other organs also have increased vascular permeability affecting lipid turnover. However, we cannot rule out that more indirect effects of apoM deficiency also play a role. Hence, even though only slightly reduced, the core body temperature was lower in $\mathrm{Apom}^{-1-}$ mice than in wildtype mice, which could indirectly stimulate BAT formation. Of note, the $\mathrm{Apom}^{-1-}$ mice could be a model of classical heat loss. This is based on the fact that increased heat loss and BAT mass in $\mathrm{Apom}^{-1-}$ mice at $23^{\circ} \mathrm{C}$ are comparable to that in the wildtype mice exposed to $4^{\circ} \mathrm{C}$ for 6 days, and that $\mathrm{Apom}^{-1-}$ mice have a lower core body temperature in thermoneutral environments. Other models with similar heat loss through the skin also may protect against diet-induced obesity (Binczek et al., 2007). Nevertheless, the postprandial clearance of plasma triglycerides was markedly increased in the $\mathrm{Apom}^{-1-}$ mice, even when mice were kept at $30^{\circ} \mathrm{C}$, which argues against a major effect of the reduced core body temperature on BAT activity. Increased adrenergic drive and central nervous system-initiated activation can increase BAT activity (Labbé et al., 2015). We have, however, not observed evidence of increased adrenergic drive in apoM-deficient mice, as judged from basic recordings of heart rate or blood pressure (data not shown). The apoM/S1P axis protects the blood-brain barrier during inflammatory stimulation (Blaho et al., 2015), but it is unknown whether the apoM/S1P axis has direct effects on central nervous system-induced stimulation of BAT.

Increased amounts of BAT, accelerated turnover of triglycerides, protection from diet-induced obesity, and improved glucose tolerance suggest a favorable phenotype related to apoM deficiency and S1P reduction. Several studies have shown a similar phenotype in animals with increased BAT activity. Hence, wild-type mice exposed to chronic cold increase the BAT activity and improve triglyceride turnover (Bartelt et al., 2011). Another estimate of BAT activity is RER reduction resembling fat utilization above carbohydrates. Housing animals at $23^{\circ} \mathrm{C}$ and $4^{\circ} \mathrm{C}$ for 6 days did not reveal any solid changes in RER between $\mathrm{Apom}^{-1-}$ mice and wild-type mice. However, in an acute cold environment, Apom $^{-1-}$ mice experienced a significant decrease in RER compared to wild-type mice after $12 \mathrm{hr}$. This supports that apoM deficiency can modify BAT activity acutely, even though the body temperature drops. Furthermore, increased BAT activity reduces hypercholesterolemia and protects against atherosclerosis (Berbée et al., 2015). ApoM

Figure 3. Deficiency of Apolipoprotein M Abrogates the Effects of $\beta_{3}$-Adrenergic Stimulation and Cold Exposure on BAT

(A) Adipose tissue mass in $A p o m^{-1-}(n=8)$ mice or wild-type $(n=8)$ mice after cold exposure $\left(4^{\circ} \mathrm{C}\right)$ for 6 days.

(B and C) Quantification of diameter (C) or numbers (B) of lipid droplets in BAT from HE-stained sections from $4 \mathrm{Apom}^{-/-}$mice and wild-type mice after cold exposure $\left(4^{\circ} \mathrm{C}\right)$ for 6 days.

(D) UCP1 in protein extracts from BAT in Apom $^{-1-}(n=5)$ mice and wild-type $(n=4)$ mice after cold exposure $\left(4^{\circ} \mathrm{C}\right)$ for 6 days. UCP1 levels were normalized with GAPDH.

(E) Cardiolipin expressed per milligram tissue wet weight of BAT from wild-type $(n=8)$ mice and Apom ${ }^{-1-}(n=8)$ mice after cold exposure $\left(4^{\circ} \mathrm{C}\right)$ for 6 days.

(F) mRNA expression in Apom $^{-1-}(n=8)$ mice calculated as percentage of the mean expression in wild-type $(n=8)$ mice after cold exposure $\left(4^{\circ} \mathrm{C}\right)$ for 6 days. FATP1, fatty acid transporter protein 1; DIO2, deiodinase iodothyronine type 2; CyCs, cytochrome $c$;

(G) Adipose tissue mass in Apom $^{-1-}(n=8)$ mice or wild-type $(n=8)$ mice after $16 \mathrm{hr}$ of acute cold exposure $\left(4^{\circ} \mathrm{C}\right)$.

(H) Adipose tissue mass in wild-type mice and $\mathrm{Apom}^{-1-}$ mice after treatment subcutaneously with either saline ( $n=4$ of each genotype) or CL316243 ( $n=5$ of each genotype). Mice were housed at $23^{\circ} \mathrm{C}$.

Error bars represent SEM. * $p<0.05$ using one-way ANOVA with Bonferroni post hoc test. $\# p<0.05$ analyzed by Student's t test with Welch's correction. See also Figure S2. 
A

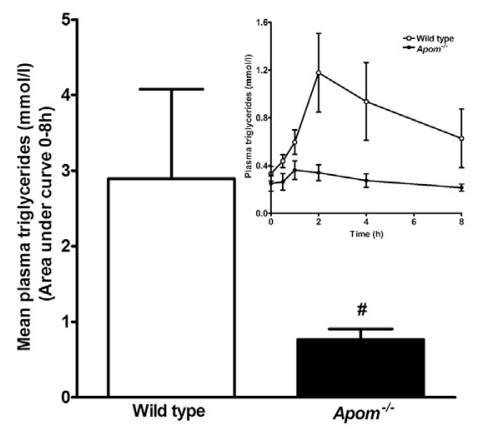

C

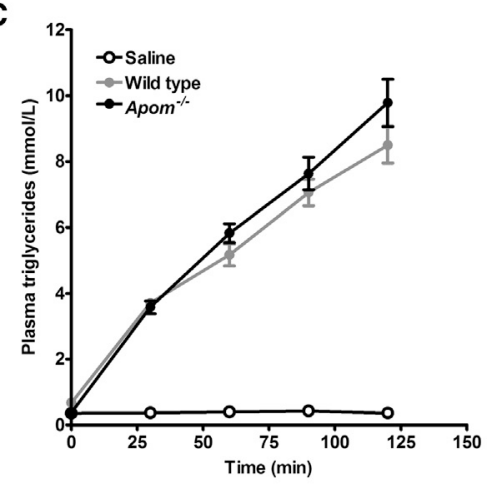

E

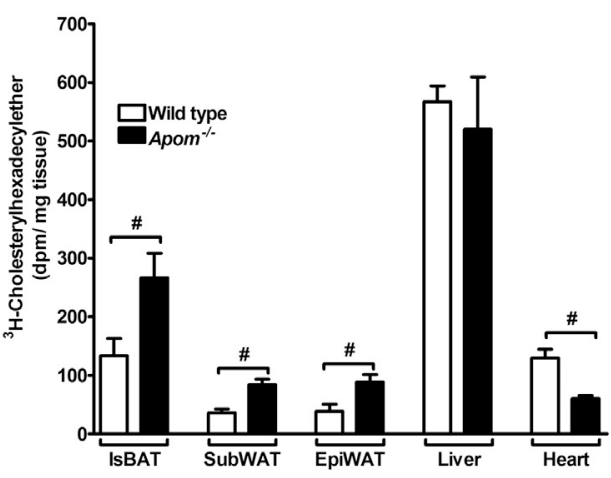

G

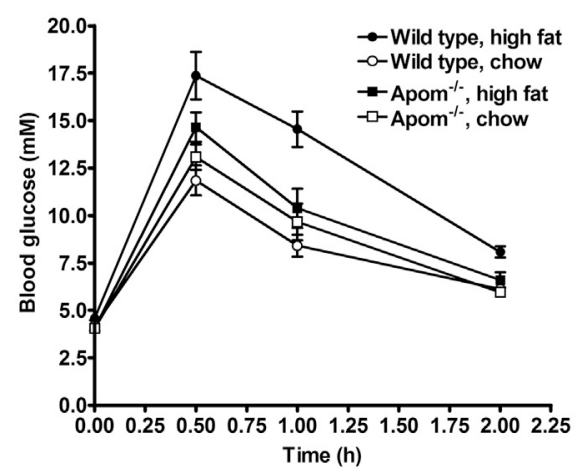

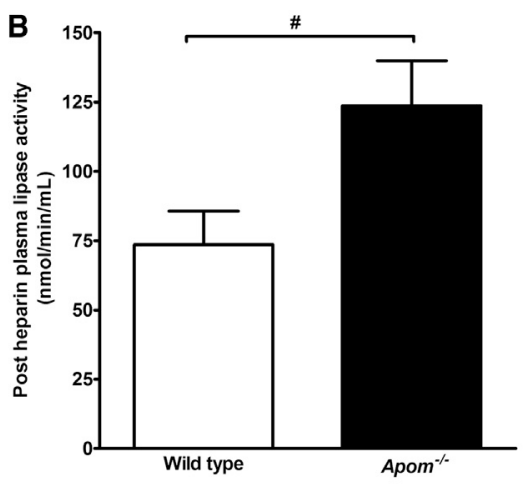

D

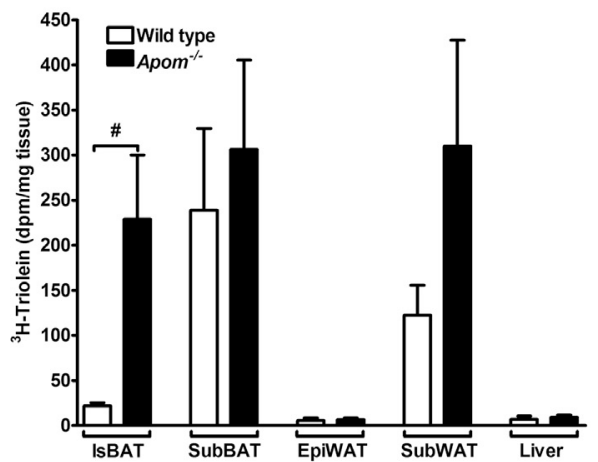

$\mathbf{F}$

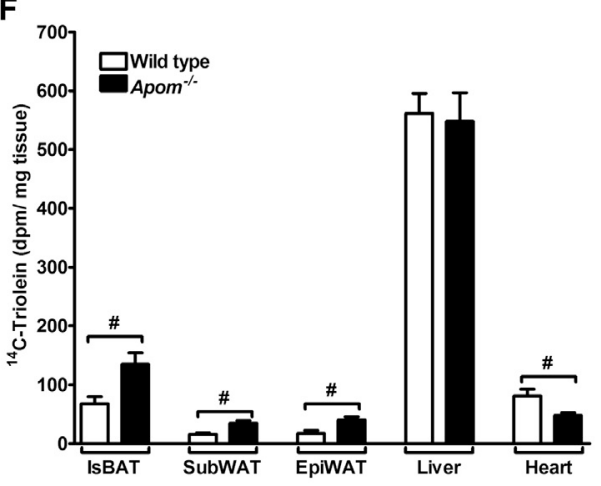

H

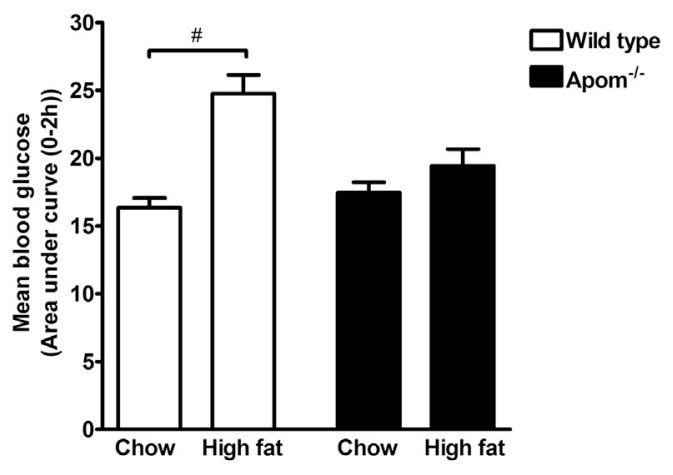

Figure 4. Apolipoprotein M Affects Postprandial Plasma Triglyceride Metabolism

(A) Area under the plasma triglyceride concentration versus time curve (insert) after an oral gavage of $300 \mu \mathrm{L}$ olive oil in $\mathrm{Apom}^{-/-}(\mathrm{n}=6)$ mice or wild-type $(\mathrm{n}=6)$ mice housed at $23^{\circ} \mathrm{C}$. 


\begin{tabular}{|c|c|c|c|c|c|c|c|}
\hline Light/Dark (12 hr) & Genotype & Activity (Counts) & Core Temperature $\left({ }^{\circ} \mathrm{C}\right)$ & Food $(\mathrm{g})$ & Water $(\mathrm{mL})$ & Energy (cal/hr) & RER \\
\hline \multicolumn{8}{|l|}{$23^{\circ} \mathrm{C}$} \\
\hline \multirow[t]{2}{*}{ light } & wild-type & $4,114 \pm 225$ & $36.1 \pm 0.0$ & $0.8 \pm 0.1$ & $0.8 \pm 0.1$ & $0.47 \pm 0.03$ & $0.89 \pm 0.01$ \\
\hline & $\mathrm{Apom}^{-1-}$ & $4,310 \pm 206$ & $35.7 \pm 0.1^{a}$ & $0.8 \pm 0.1$ & $0.6 \pm 0.1$ & $0.43 \pm 0.03$ & $0.88 \pm 0.01$ \\
\hline \multirow[t]{2}{*}{ dark } & wild-type & $10,421 \pm 1,335$ & $37.0 \pm 0.1$ & $2.9 \pm 0.2$ & $2.7 \pm 0.1$ & $0.59 \pm 0.05$ & $1.03 \pm 0.01$ \\
\hline & Apom $^{-1-}$ & $12,758 \pm 1,523$ & $36.6 \pm 0.1^{a}$ & $2.9 \pm 0.2$ & $2.5 \pm 0.1$ & $0.54 \pm 0.04$ & $1.04 \pm 0.01$ \\
\hline \multicolumn{8}{|l|}{$30^{\circ} \mathrm{C}$} \\
\hline \multirow[t]{2}{*}{ light } & wild-type & $4,105 \pm 131$ & $36.1 \pm 0.1$ & $0.6 \pm 0.1$ & $0.9 \pm 0.1$ & $0.25 \pm 0.01$ & $0.89 \pm 0.00$ \\
\hline & Apom $^{-1-}$ & $4,701 \pm 216^{a, b}$ & $35.8 \pm 0.1^{a}$ & $0.7 \pm 0.1$ & $0.8 \pm 0.1$ & $0.24 \pm 0.02$ & $0.91 \pm 0.01^{b}$ \\
\hline \multirow[t]{2}{*}{ dark } & wild-type & $10,938 \pm 1,266$ & $37.2 \pm 0.1$ & $1.7 \pm 0.1$ & $2.9 \pm 0.3$ & $0.35 \pm 0.02$ & $0.98 \pm 0.01$ \\
\hline & $\mathrm{Apom}^{-1-}$ & $12,031 \pm 997$ & $37.1 \pm 0.1$ & $1.8 \pm 0.1$ & $2.8 \pm 0.1$ & $0.34 \pm 0.03$ & $0.99 \pm 0.01$ \\
\hline \multicolumn{8}{|l|}{ Fasting } \\
\hline \multirow[t]{2}{*}{ light } & wild-type & $3,524 \pm 157$ & $34.6 \pm 0.3$ & - & $1.4 \pm 0.1$ & $0.40 \pm 0.06$ & $0.76 \pm 0.01$ \\
\hline & $\mathrm{Apom}^{-1-}$ & $4,073 \pm 603$ & $34.6 \pm 0.3$ & - & $1.3 \pm 0.1$ & $0.26 \pm 0.03^{b}$ & $0.75 \pm 0.01$ \\
\hline \multirow[t]{2}{*}{ dark } & wild-type & $16,723 \pm 1,796$ & $35.8 \pm 0.1$ & - & $2.1 \pm 0.4$ & $0.57 \pm 0.07$ & $0.78 \pm 0.01$ \\
\hline & $\mathrm{Apom}^{-1-}$ & $20,935 \pm 2,574$ & $35.4 \pm 0.3$ & - & $1.9 \pm 0.3$ & $0.43 \pm 0.06$ & $0.77 \pm 0.01$ \\
\hline \multicolumn{8}{|l|}{ Re-fed } \\
\hline \multirow[t]{2}{*}{ light } & wild-type & $4,875 \pm 305$ & $35.9 \pm 0.0$ & $1.4 \pm 0.1$ & $1.6 \pm 0.1$ & $0.56 \pm 0.06$ & $1.02 \pm 0.01$ \\
\hline & Apom $^{-1-}$ & $5,102 \pm 232$ & $35.7 \pm 0.1^{a}$ & $1.1 \pm 0.1^{b}$ & $1.2 \pm 0.1^{b}$ & $0.43 \pm 0.05$ & $0.97 \pm 0.01^{\mathrm{b}}$ \\
\hline \multirow[t]{2}{*}{ dark } & wild-type & $10,394 \pm 495$ & $36.8 \pm 0.1$ & $2.6 \pm 0.1$ & $3.6 \pm 0.2$ & $0.66 \pm 0.07$ & $1.04 \pm 0.01$ \\
\hline & Apom $^{-1-}$ & $11,709 \pm 788$ & $36.5 \pm 0.1^{a}$ & $2.5 \pm 0.2$ & $3.1 \pm 0.2$ & $0.51 \pm 0.06$ & $1.04 \pm 0.01$ \\
\hline \multicolumn{8}{|l|}{$4^{\circ} \mathrm{C}$} \\
\hline \multirow[t]{2}{*}{ light $\left(4^{\circ} \mathrm{C}\right)$} & wild-type & $5,217 \pm 425$ & $35.5 \pm 0.1$ & $2.0 \pm 0.1$ & $2.8 \pm 0.3$ & $0.75 \pm 0.04$ & $0.86 \pm 0.01$ \\
\hline & Apom $^{-1-}$ & $5,263 \pm 309$ & $33.7 \pm 0.8^{a}$ & $1.7 \pm 0.1$ & $2.7 \pm 0.2$ & $0.69 \pm 0.05$ & $0.84 \pm 0.02$ \\
\hline \multirow[t]{2}{*}{ dark } & wild-type & $8,218 \pm 587$ & $36.7 \pm 0.1$ & $2.9 \pm 0.2$ & $5.0 \pm 0.3$ & $0.62 \pm 0.04$ & $1.05 \pm 0.01$ \\
\hline & Apom $^{-1-}$ & $8,986 \pm 420$ & $36.5 \pm 0.1$ & $2.9 \pm 0.2$ & $4.7 \pm 0.1$ & $0.58 \pm 0.04$ & $1.09 \pm 0.01^{b}$ \\
\hline \multirow[t]{2}{*}{ light } & wild-type & $4,799 \pm 490$ & $36.5 \pm 0.1$ & $1.6 \pm 0.2$ & $4.1 \pm 1.1$ & $0.51 \pm 0.07$ & $0.94 \pm 0.02$ \\
\hline & $\mathrm{Apom}^{-1-}$ & $5,821 \pm 226^{b}$ & $36.2 \pm 0.1$ & $1.3 \pm 0.1$ & $4.0 \pm 0.2$ & $0.69 \pm 0.07^{b}$ & $0.95 \pm 0.02$ \\
\hline \multirow[t]{2}{*}{ dark $\left(4^{\circ} \mathrm{C}\right)$} & wild-type & $8,771 \pm 865$ & $36.1 \pm 0.1$ & $2.8 \pm 0.3$ & $2.7 \pm 0.3$ & $1.01 \pm 0.10$ & $0.86 \pm 0.04$ \\
\hline & Apom $^{-1-}$ & $7,688 \pm 637$ & $35.6 \pm 0.2^{a}$ & $3.5 \pm 0.3^{b}$ & $2.2 \pm 0.2$ & $1.06 \pm 0.11$ & $0.88 \pm 0.03$ \\
\hline
\end{tabular}

Food, water, $\mathrm{O}_{2}, \mathrm{CO}_{2}$, activity, and temperature were recorded. The animals were housed at $23^{\circ} \mathrm{C}$, fasted for $24 \mathrm{hr}$, refed, and housed at $30^{\circ} \mathrm{C}, 23^{\circ} \mathrm{C}$, and $4^{\circ} \mathrm{C}$. See also Figures S3 and S4 and Table S1.

${ }^{a}$ Values are means \pm SEMs, $n=8$ in each group, $p<0.05$ using Student's $t$ test.

bValues are means \pm SEMs, $n=8$ in each group, $p<0.05$ using ANCOVA statistical testing.

overexpression in mice can increase cholesterol efflux from macrophages, protect against oxidation of LDL, and reduce atherosclerosis (Christoffersen et al., 2008). However, Apom $^{-1-} / \mathrm{d} l \mathrm{r}^{-/-}$mice had surprisingly reduced levels of cholesterol and atherosclerosis (Christoffersen et al., 2010). Whether this unexplained phenotype could be related to the hereindescribed increased BAT activity in Apom $^{-1-}$ mice is unknown, but it has been shown that BAT activation protects against atherosclerotic development (Berbée et al., 2015).
The increased turnover of postprandial triglycerides in $\mathrm{Apom}^{-1-}$ mice was associated with the increased uptake of fatty acids and artificial double-labeled whole lipoprotein particles in BAT. Also, BAT displayed increased vascular permeability in $\mathrm{Apom}^{-1-}$ mice. The latter finding likely reflects diminished $\mathrm{S}_{1 \mathrm{P}}$ receptor stimulation (Christensen et al., 2016). The increased permeability may provide easier access for lipoproteins to the BAT adipocytes and even endothelial-bound $\mathrm{LPL}$, which could contribute to accelerated tissue uptake of

(B) Plasma lipase activity 10 min after intravenous injection of heparin in Apom $^{-/-}(n=26)$ mice or wild-type $(n=22)$ mice

(C) Plasma triglyceride concentrations after intravenous injection of Triton WR-1339 in Apom ${ }^{-1-}(n=5)$ mice or wild-type $(n=5)$ mice.

(D) Tissue uptake of ${ }^{3} \mathrm{H}$-triolein $4 \mathrm{hr}$ after oral gavage with $300 \mu \mathrm{L}^{3} \mathrm{H}$-triolein-containing olive oil in Apom ${ }^{-1-}(\mathrm{n}=6)$ mice and wild-type $(\mathrm{n}=6)$ mice.

$\left(\mathrm{E}\right.$ and $\mathrm{F}$ ) Tissue uptake of ${ }^{3} \mathrm{H}$-cholesterylhexadecylether $(\mathrm{E})$ and ${ }^{14} \mathrm{C}$-triolein $(\mathrm{F}) 10$ minutes after intravenous injection of double-labeled triglyceride-rich lipoproteins in Apom $^{-1-}(n=9)$ mice and wild-type $(n=8)$ mice.

$(\mathrm{G}$ and $\mathrm{H})$ Blood glucose $(\mathrm{G})$ and area under the blood glucose concentration $(\mathrm{H})$ versus time curve after an intraperitoneal injection of glucose in $A p o m^{-/-}(\mathrm{n}=8)$ mice or wild-type ( $n=7-8$ ) mice fed chow (open symbols) or high-fat diet (filled symbols) for 10 weeks $(\mathrm{H})$.

Error bars represent SEM. \# $\mathrm{p}<0.05$ analyzed by Student's t test with Welch's correction. See also Figure S3 and Table S1. 
A

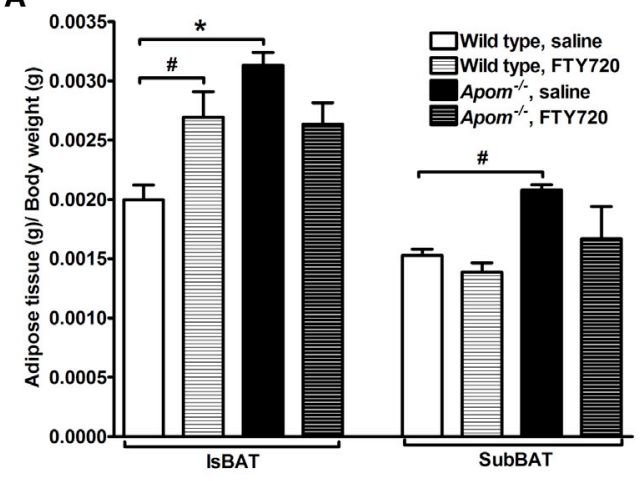

C

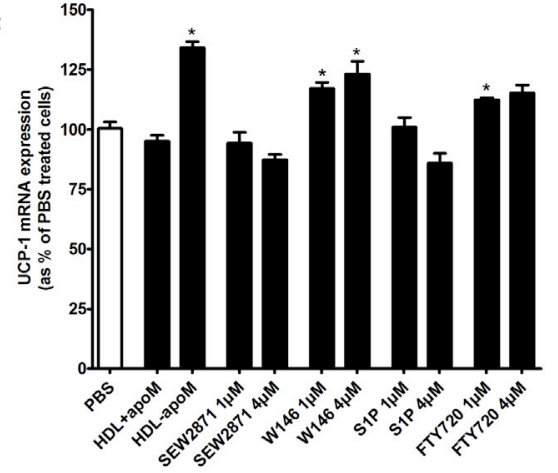

E
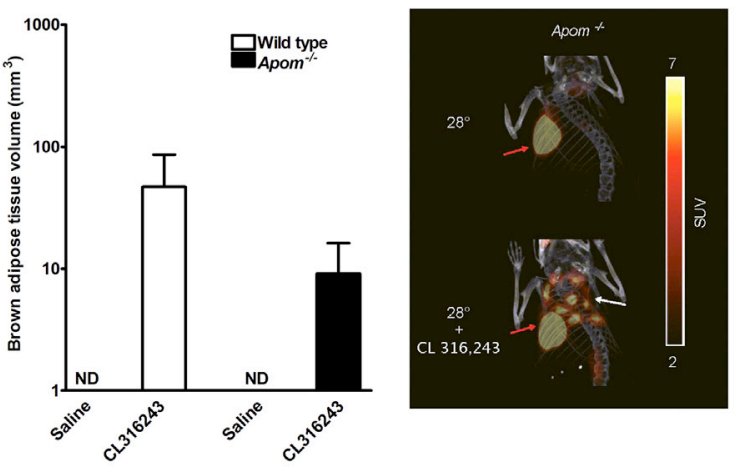

G

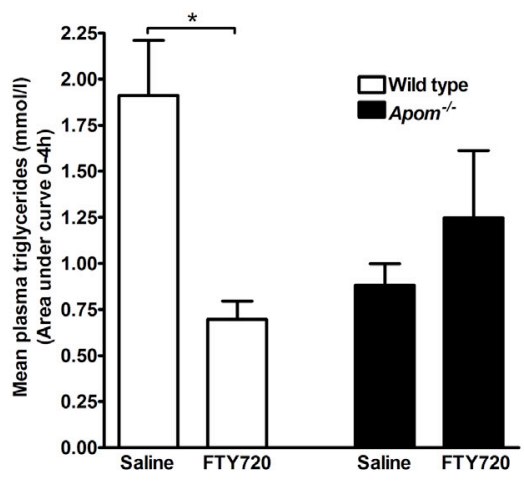

B

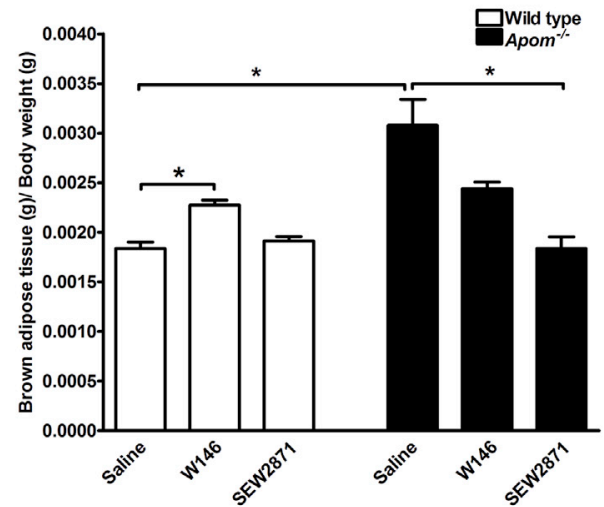

D

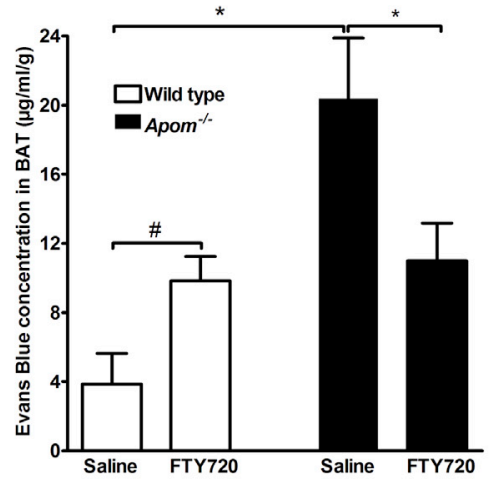

$\mathbf{F}$

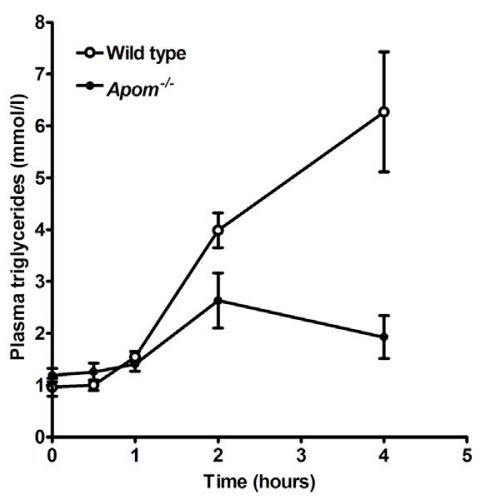

H

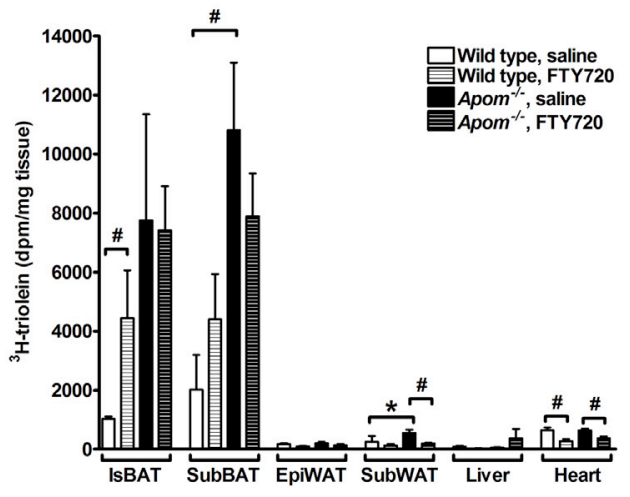


triglycerides (Williams and Fisher, 2011). However, altered lipid metabolism in other tissues also may play a role. Thus, the increased clearance of postprandial triglycerides was seen even at $30^{\circ} \mathrm{C}$, when BAT uptake of glucose was diminished. Indeed, apoM deficiency altered the gene expression profile of WAT and increased postheparin LPL concentrations in plasma. Several apolipoproteins in very low-density lipoproteins (VLDLs) and chylomicrons, such as apoCI, apoCll, apoCIII, and apoAV, regulate and interact with LPL (Clavey et al., 1995; Gangabadage et al., 2008; Goldberg et al., 1990; Shen et al., 2002). ApoM also is present on chylomicrons and VLDLs (Xu and Dahlbäck, 1999), even though only $4 \%-5 \%$ of plasma apoM is bound to other lipoproteins than HDLs (Christoffersen et al., 2006). We do not suspect, however, that a direct interaction with LPL plays a major role, because the plasma concentration of apoM in non-HDLs is rather low $(<50 \mu \mathrm{mol} / \mathrm{L})$ and because BAT uptake of artificial double-labeled whole particles was increased in the $\mathrm{Apom}^{-/-}$ mice. Notably, plasma ANGPLT4, which regulates the activity of LPL (Dijk et al., 2015; Köster et al., 2005), was similar in $\mathrm{Apom}^{-1-}$ mice and wild-type mice (data not shown).

Interestingly, previous results support that the S1P system indeed affects triglyceride metabolism. Thus, in mice, sphingosine kinase 2 inhibition reduced both plasma S1P and triglycerides (Poti et al., 2012; Poti et al., 2015), whereas S1P-lyase deficiency increased plasma S1P and triglycerides (Bektas et al., 2010). Moreover, FTY720 accelerates lipolysis in vitro (Moon et al., 2012), implying direct effects of S1P on adipocyte biology. When used for its $\mathrm{S}_{1} \mathrm{P}_{1}$-agonizing effects in treating patients with multiple sclerosis, dyslipidemia is a well-accepted adverse effect of FTY720 (Kim et al., 2015). In the present study, both FTY720 and the $\mathrm{S}_{1} \mathrm{P}_{1}$ antagonist $\mathrm{W} 146$ increased BAT mass and reduced postprandial triglycerides in wild-type mice. Furthermore, the primary source of S1P, ceramide, also has been investigated recently for its roles in browning of adipocytes and metabolism (Chaurasia et al., 2016). The study found that the inhibition of ceramide induces browning of subcutaneous WAT, accelerates energy expenditure, and protects against diet-induced obesity. However, the authors did not find any significant effect of ceramide on BAT. These data and the present study support that sphingolipids can influence the metabolic activity and insulin sensitivity in adipose tissue. They also suggest that an increased amount of and activity in BAT are likely the result of a specific phenotype induced by S1P/apoM and its receptors. Hence, the present data should spark investigations to unravel a putative beneficial role of inhibiting the $\mathrm{S}_{1} \mathrm{P}_{1}$ in, e.g., obesity and increased postprandial lipedema. Indeed, increased activity of BAT in humans has been associated with improved metabolic health from increased lipid metabolism, glucose uptake, and weight loss (Bartelt and Heeren, 2014; Cawthorne et al., 1984; Peirce and Vidal-Puig, 2013; Vallerand et al., 1986), and obese individuals also have reduced levels of BAT (van Marken Lichtenbelt et al., 2009). Inhibition of the apoM/S1P axis may provide a tool to address the extent to which stimulation of BAT is an effective means for improving metabolism in adult humans.

\section{EXPERIMENTAL PROCEDURES}

\section{Animals}

Mice were housed at the Panum Institute (University of Copenhagen) in a temperature-controlled facility with a 12-hr dark/light cycle and fed standard chow or a high-fat-containing diet. Only female mice were used throughout the study. All of the procedures were approved by the Animal Experiments Inspectorate, Ministry of Justice, Denmark.

\section{Isolation of Tissue}

Animals were anesthetized before blood sampling from the orbital vein; animals were perfused with saline before dissection of the liver, epiWAT, subWAT, quadriceps muscle, IsBAT, and subscapular BAT.

\section{Plasma Analysis}

Plasma triglycerides were measured with enzymatic kits (GPO Trinder, Sigma-Aldrich). Lipoprotein lipase activity was evaluated with the Lipase Activity Assay (cat. no. 700640, Cayman Chemical). To explore the secretion rate of triglyceride from the liver, Triton WR-1339 $(0.5 \mathrm{~g} / \mathrm{kg}$ body weight $[B W])$ was injected intravenously (i.v.) into mice after fasting overnight $(n=5)$.

\section{RNA and Protein Extraction}

RNA was isolated with Trizol (Invitrogen). First-strand cDNA synthesis was performed using High Capacity cDNA reverse Transcription Kit (Applied Biosystems) and quantitative real-time PCR analysis was done with a TaqMan ABI PRISM 7900HT Sequence Detection System (Applied Biosystems). UCP1 protein levels were analyzed by Western blotting using an anti-mouse UCP1 antibody (Abcam 23841). Glyceraldehyde-3-phosphate dehydrogenase (GAPDH) was detected with an antibody (SC257787) from Santa Cruz Biotechnology.

\section{Cardiolipin Measurement}

Lipids were extracted with chloroform/methanol from BAT as described (Bartels et al., 2002) from Apom $^{-1-}(n=8)$ mice and wild-type $(n=7-8)$ mice housed at $23^{\circ} \mathrm{C}$ or $4^{\circ} \mathrm{C}$. The extracts were analyzed by quantitative thin-layer chromatography.

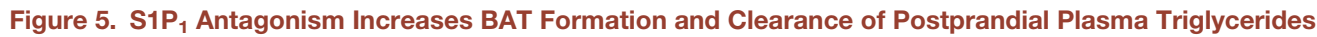

(A) BAT mass in wild-type $(n=6)$ mice and Apom $^{-1-}(n=7)$ mice treated with saline or FTY720.

(B) IsBAT mass in wild-type mice and $\mathrm{Apom}^{-1-}$ mice treated with $\mathrm{S}_{1} \mathrm{P}_{1}$ agonist SEW2871 $(\mathrm{n}=6-7)$, S1P 1 antagonist W146 $(\mathrm{n}=6-8)$, or saline $(\mathrm{n}=10-14)$.

(C) UCP1 mRNA expression in 3T3-L1 cells differentiated into beige adipocytes in the present of either phosphate-buffered saline (PBS), HDL+apoM, HDL-apoM, S1P, SEW2871, W146, or FTY720.

(D) Endothelial permeability was measured as uptake of Evans Blue per gram BAT.

(E) BAT volume measured by PET-CT scanning in mice $(n=4-5)$ receiving either saline or the $\beta_{3}$-agonist CL316243 before FDG. PET-CT images are from representative $\mathrm{Apom}^{-1-}$ mice housed at $30^{\circ} \mathrm{C}$. White and red arrows indicate FDG uptake in BAT and heart, respectively.

(F) Plasma triglyceride concentrations after an oral gavage of $300 \mu \mathrm{L}$ olive oil in wild-type $(\mathrm{n}=6)$ mice and $A p o m^{-\prime-}(\mathrm{n}=7)$ mice housed for 7 days at $30^{\circ} \mathrm{C}$.

(G) Area under plasma triglyceride concentration versus time curve $(4 \mathrm{hr})$ after oral gavage of $300 \mu \mathrm{L} \mathrm{olive} \mathrm{oil} \mathrm{in} \mathrm{Apom}^{-1-}(\mathrm{n}=7)$ mice or control $(\mathrm{n}=7)$ mice treated with saline or FTY720 before fat challenge.

(H) Tissue uptake of ${ }^{3} \mathrm{H}$-triolein $4 \mathrm{hr}$ after oral gavage with $300 \mu \mathrm{L}$ triolein-containing olive oil in Apom ${ }^{-/-}(\mathrm{n}=6)$ mice and wild-type $(\mathrm{n}=6)$ mice treated with FTY720 or saline.

Error bars represent SEM. *p $<0.05$ using one-way ANOVA with Bonferroni post hoc test. \#p $<0.05$ analyzed by Student's $t$ test with Welch's correction when appropriate. See also Figures S5 and S6. 
Histology

BAT and WAT isolated from Apom ${ }^{-1-}(n=4)$ and wild-type $(n=4)$ mice sacrificed at $23^{\circ} \mathrm{C}$ or $4^{\circ} \mathrm{C}$ were embedded in paraffin and stained with Mayer's hematoxylin and eosin (HE; Dako). Histological analyses were conducted with a Leitz Diaplan (Leica) microscope. Pictures were acquired with a Leica DFC290 digital camera and analyzed with the Leica IM50 software.

\section{Thermographic Measurement}

Tail or body surface temperature in animals was measured with a FLIR E6 thermographic camera at a distance of $15 \mathrm{~cm}$. Recordings were repeated at least 4 times at each time point and analyzed with FLIR Tool+ and FLIR ResearchIR.

\section{Clearance of Plasma Triglycerides}

After overnight fasting, mice received olive oil $(300 \mu \mathrm{L})$ or olive oil supplemented with ${ }^{3} \mathrm{H}$-triolein by oral gavage. After $240 \mathrm{~min}$, the animals were sacrificed and perfused with $0.9 \% \mathrm{NaCl}$. Tissue biopsies were dissolved in Solvable (PerkinElmer). ${ }^{3} \mathrm{H}$ was counted in a Wallac 1409 Liquid Scintillation Counter (PerkinElmer). To measure whole triglyceride particle uptake in tissues, mice were injected intravenously with triglyceride-rich lipoproteins labeled with ${ }^{14} \mathrm{C}$-triolein and ${ }^{3} \mathrm{H}$-cholesterylhexadecylether as described (Bartelt et al., 2011).

\section{Metabolic Phenotyping}

Apom $^{-/-}(\mathrm{n}=8)$ mice and wild-type $(\mathrm{n}=8)$ mice were housed individually and monitored with an indirect calorimetry system (PhenoMaster, TSE Systems, Germany). The animals were housed at $23^{\circ} \mathrm{C}$, fasted for $24 \mathrm{hr}$, refed, and housed at $30^{\circ} \mathrm{C}$, at $23^{\circ} \mathrm{C}$, and finally at $4^{\circ} \mathrm{C}$. Animals were acclimatized for 3 days at each temperature before recordings were made. To estimate the effect of acute cold exposure, Apom ${ }^{-1-}(\mathrm{n}=8)$ mice and wild-type $(\mathrm{n}=8)$ mice were housed at $30^{\circ} \mathrm{C}$ for 3 days and moved directly into environmental chambers (TSE Systems) at $4^{\circ} \mathrm{C}$ for $16 \mathrm{hr}$. To test the effect of a high-fat diet, Apom $^{-1-}(\mathrm{n}=8)$ mice and wild-type $(\mathrm{n}=8)$ mice were housed at $23^{\circ} \mathrm{C}$ for 3 days, fasted for $12 \mathrm{hr}$, and refed a high-fat diet.

Vascular Permeability

Mice received an intravenous injection of Evans Blue. Evans Blue uptake in BAT was measured after 30 min as described (Christoffersen et al., 2011).

\section{PET-CT}

An intravenous injection of $10 \mathrm{MBq}$ FDG was administered to mice $1 \mathrm{hr}$ before PET-CT scanning (Inveon multimodality PET-CT scanner, Siemens).

\section{Drug Treatment}

Fingolimod (Sigma-Aldrich) or saline was administered by oral gavage (0.5 mg/kg body weight mice) (Blaho et al., 2015). SEW2871 (10 mg/kg; S3944, Sigma-Aldrich, Brøndby, Denmark) $(10 \mathrm{mg} / \mathrm{kg})$, W146 $(10 \mathrm{mg} / \mathrm{kg}$; W1020, Sigma-Aldrich), and $\beta_{3}$ receptor agonist CL316243 $(1 \mathrm{mg} / \mathrm{kg})$ or saline were injected subcutaneously (Bartelt et al., 2013).

MRI

Animals were acclimatized at $23^{\circ} \mathrm{C}$ for 7 days before fat and lean body mass was measured with MRI with EchoMRI 4in1-700 (Houston, TX, USA).

\section{Statistical Analysis}

Differences between groups were analyzed with one-way ANOVA, post hoc test, and Student $t$ test using Welch's correction for unequal variances whenever appropriate. For statistical evaluation of the data obtained in metabolic cages, SPSS was used following the appropriate guidelines (Speakman et al., 2013).

\section{SUPPLEMENTAL INFORMATION}

Supplemental Information includes Supplemental Experimental Procedures, six figures, and one table and can be found with this article online at https:// doi.org/10.1016/j.celrep.2017.12.029.

\section{ACKNOWLEDGMENTS}

We thank Charlotte Wandel, Lis Schütt Nielsen, and Birgitte Nielsen from the Department of Clinical Biochemistry, Rigshospitalet, Copenhagen, Denmark, for technical assistance and the staff of the Metabolic Core Facility at Panum Institute for helpful assistance. The project was funded by the Danish Council for Independent Research|Medical Sciences (grant 1331-00337B to L.B.N.), the Lundbeck Foundation (grant R126-2012-12400 to C.C.), the Novo Nordisk Foundation Excellence Project (grant NNF13OC0003898 to C.C.), the Department of Biomedical Sciences, University of Copenhagen (to A.B.), and the Deutsche Forschungsgemeinschaft (grant HE3645/7-1 to J.H.).

\section{AUTHOR CONTRIBUTIONS}

C.C. designed the study, performed experiments and data analysis, and wrote the first draft. C.K.F., A.B., and P.M.C. performed animal experiments and data analyses; A.N.M. and B.H. performed and designed metabolic experiments and interpretation of data. M.H. and J.H. performed metabolic turnover studies using double-labeled lipoproteins and tissue uptake calculations. C.H.N. and A.K. performed PET-CT scanning and data analysis. L.B.N. designed the study, evaluated data, and critically supervised the first draft. All authors have read and approved the final paper.

\section{DECLARATION OF INTERESTS}

The authors declare no competing interests.

Received: June 28, 2017

Revised: October 25, 2017

Accepted: December 7, 2017

Published: January 2, 2018

\section{REFERENCES}

Bartels, E.D., Lauritsen, M., and Nielsen, L.B. (2002). Hepatic expression of microsomal triglyceride transfer protein and in vivo secretion of triglyceride-rich lipoproteins are increased in obese diabetic mice. Diabetes 51 1233-1239.

Bartelt, A., and Heeren, J. (2014). Adipose tissue browning and metabolic health. Nat. Rev. Endocrinol. 10, 24-36.

Bartelt, A., Bruns, O.T., Reimer, R., Hohenberg, H., Ittrich, H., Peldschus, K. Kaul, M.G., Tromsdorf, U.I., Weller, H., Waurisch, C., et al. (2011). Brown adipose tissue activity controls triglyceride clearance. Nat. Med. 17, 200-205.

Bartelt, A., Weigelt, C., Cherradi, M.L., Niemeier, A., Tödter, K., Heeren, J., and Scheja, L. (2013). Effects of adipocyte lipoprotein lipase on de novo lipogenesis and white adipose tissue browning. Biochim. Biophys. Acta 1831 934-942.

Bektas, M., Allende, M.L., Lee, B.G., Chen, W., Amar, M.J., Remaley, A.T., Saba, J.D., and Proia, R.L. (2010). Sphingosine 1-phosphate lyase deficiency disrupts lipid homeostasis in liver. J. Biol. Chem. 285, 10880-10889.

Berbée, J.F., Boon, M.R., Khedoe, P.P., Bartelt, A., Schlein, C., Worthmann, A., Kooijman, S., Hoeke, G., Mol, I.M., John, C., et al. (2015). Brown fat activation reduces hypercholesterolaemia and protects from atherosclerosis development. Nat. Commun. 6, 6356.

Binczek, E., Jenke, B., Holz, B., Günter, R.H., Thevis, M., and Stoffel, W. (2007). Obesity resistance of the stearoyl-CoA desaturase-deficient (scd1-/-) mouse results from disruption of the epidermal lipid barrier and adaptive thermoregulation. Biol. Chem. 388, 405-418.

Blaho, V.A., Galvani, S., Engelbrecht, E., Liu, C., Swendeman, S.L., Kono, M. Proia, R.L., Steinman, L., Han, M.H., and Hla, T. (2015). HDL-bound sphingosine-1-phosphate restrains lymphopoiesis and neuroinflammation. Nature 523, 342-346.

Brinkmann, V., Davis, M.D., Heise, C.E., Albert, R., Cottens, S., Hof, R., Bruns C., Prieschl, E., Baumruker, T., Hiestand, P., et al. (2002). The immune 
modulator FTY720 targets sphingosine 1-phosphate receptors. J. Biol. Chem. 277, 21453-21457.

Camerer, E., Regard, J.B., Cornelissen, I., Srinivasan, Y., Duong, D.N., Palmer, D., Pham, T.H., Wong, J.S., Pappu, R., and Coughlin, S.R. (2009). Sphingosine-1-phosphate in the plasma compartment regulates basal and inflammation-induced vascular leak in mice. J. Clin. Invest. 119, 1871-1879.

Cannon, B., and Nedergaard, J. (2004). Brown adipose tissue: function and physiological significance. Physiol. Rev. 84, 277-359.

Cawthorne, M.A., Carroll, M.J., Levy, A.L., Lister, C.A., Sennitt, M.V., Smith, S.A., and Young, P. (1984). Effects of novel beta-adrenoceptor agonists on carbohydrate metabolism: relevance for the treatment of non-insulin-dependent diabetes. Int. J. Obes. 8 (Supp/ 1), 93-102.

Chaurasia, B., Kaddai, V.A., Lancaster, G.I., Henstridge, D.C., Sriram, S., Galam, D.L., Gopalan, V., Prakash, K.N., Velan, S.S., Bulchand, S., et al. (2016). Adipocyte ceramides regulate subcutaneous adipose browning, inflammation, and metabolism. Cell Metab. 24, 820-834.

Christensen, P.M., Liu, C.H., Swendeman, S.L., Obinata, H., Qvortrup, K., Nielsen, L.B., Hla, T., Di, L.A., and Christoffersen, C. (2016). Impaired endothelial barrier function in apolipoprotein M-deficient mice is dependent on sphingosine-1-phosphate receptor 1. FASEB J 30, 2351-2359.

Christoffersen, C., Nielsen, L.B., Axler, O., Andersson, A., Johnsen, A.H., and Dahlbäck, B. (2006). Isolation and characterization of human apolipoprotein M-containing lipoproteins. J. Lipid Res. 47, 1833-1843.

Christoffersen, C., Jauhiainen, M., Moser, M., Porse, B., Ehnholm, C., Boesl, M., Dahlbäck, B., and Nielsen, L.B. (2008). Effect of apolipoprotein M on high density lipoprotein metabolism and atherosclerosis in low density lipoprotein receptor knock-out mice. J. Biol. Chem. 283, 1839-1847.

Christoffersen, C., Pedersen, T.X., Gordts, P.L., Roebroek, A.J., Dahlbäck, B., and Nielsen, L.B. (2010). Opposing effects of apolipoprotein $m$ on catabolism of apolipoprotein B-containing lipoproteins and atherosclerosis. Circ. Res. 106, 1624-1634.

Christoffersen, C., Obinata, H., Kumaraswamy, S.B., Galvani, S., Ahnström, J., Sevvana, M., Egerer-Sieber, C., Muller, Y.A., Hla, T., Nielsen, L.B., and Dahlbäck, B. (2011). Endothelium-protective sphingosine-1-phosphate provided by HDL-associated apolipoprotein M. Proc. Natl. Acad. Sci. USA 108, 96139618.

Clavey, V., Lestavel-Delattre, S., Copin, C., Bard, J.M., and Fruchart, J.C. (1995). Modulation of lipoprotein B binding to the LDL receptor by exogenous lipids and apolipoproteins $\mathrm{Cl}, \mathrm{CII}, \mathrm{CIII}$, and E. Arterioscler. Thromb. Vasc. Biol. 15, 963-971.

Davidson, W.S., Silva, R.A., Chantepie, S., Lagor, W.R., Chapman, M.J., and Kontush, A. (2009). Proteomic analysis of defined HDL subpopulations reveals particle-specific protein clusters: relevance to antioxidative function. Arterioscler. Thromb. Vasc. Biol. 29, 870-876.

Dijk, W., Heine, M., Vergnes, L., Boon, M.R., Schaart, G., Hesselink, M.K., Reue, K., van Marken Lichtenbelt, W.D., Olivecrona, G., Rensen, P.C., et al. (2015). ANGPTL4 mediates shuttling of lipid fuel to brown adipose tissue during sustained cold exposure. eLife 4, e08428.

Duan, J., Dahlbäck, B., and Villoutreix, B.O. (2001). Proposed lipocalin fold for apolipoprotein $\mathrm{M}$ based on bioinformatics and site-directed mutagenesis. FEBS Lett. 499, 127-132.

Faber, C., Zhu, Z.J., Castellino, S., Wagner, D.S., Brown, R.H., Peterson, R.A., Gates, L., Barton, J., Bickett, M., Hagerty, L., et al. (2014). Cardiolipin profiles as a potential biomarker of mitochondrial health in diet-induced obese mice subjected to exercise, diet-restriction and ephedrine treatment. J. Appl. Toxicol. 34, 1122-1129.

Gangabadage, C.S., Zdunek, J., Tessari, M., Nilsson, S., Olivecrona, G., and Wijmenga, S.S. (2008). Structure and dynamics of human apolipoprotein CIII. J. Biol. Chem. 283, 17416-17427.

Garcia, J.G., Liu, F., Verin, A.D., Birukova, A., Dechert, M.A., Gerthoffer, W.T. Bamberg, J.R., and English, D. (2001). Sphingosine 1-phosphate promotes endothelial cell barrier integrity by Edg-dependent cytoskeletal rearrangement. J. Clin. Invest. 108, 689-701.
Goldberg, I.J., Scheraldi, C.A., Yacoub, L.K., Saxena, U., and Bisgaier, C.L. (1990). Lipoprotein ApoC-II activation of lipoprotein lipase. Modulation by apolipoprotein A-IV. J. Biol. Chem. 265, 4266-4272.

Golozoubova, V., Hohtola, E., Matthias, A., Jacobsson, A., Cannon, B., and Nedergaard, J. (2001). Only UCP1 can mediate adaptive nonshivering thermogenesis in the cold. FASEB J. 15, 2048-2050.

Grigoriadis, N., and van Pesch, V.; ParadigMS Group (2015). A basic overview of multiple sclerosis immunopathology. Eur. J. Neurol. 22 (Supp/ 2), 3-13.

Hanssen, M.J., Hoeks, J., Brans, B., van der Lans, A.A., Schaart, G., van den Driessche, J.J., Jörgensen, J.A., Boekschoten, M.V., Hesselink, M.K., Havekes, B., et al. (2015). Short-term cold acclimation improves insulin sensitivity in patients with type 2 diabetes mellitus. Nat. Med. 21, 863-865.

Horton, E.S. (1983). Role of environmental factors in the development of noninsulin-dependent diabetes mellitus. Am. J. Med. 75 (5B), 32-40.

Karuna, R., Park, R., Othman, A., Holleboom, A.G., Motazacker, M.M., Sutter, I., Kuivenhoven, J.A., Rohrer, L., Matile, H., Hornemann, T., et al. (2011). Plasma levels of sphingosine-1-phosphate and apolipoprotein $\mathrm{M}$ in patients with monogenic disorders of HDL metabolism. Atherosclerosis 219, 855-863. Khedoe, P.P., Hoeke, G., Kooijman, S., Dijk, W., Buijs, J.T., Kersten, S., Havekes, L.M., Hiemstra, P.S., Berbée, J.F., Boon, M.R., and Rensen, P.C. (2015). Brown adipose tissue takes up plasma triglycerides mostly after lipolysis. J. Lipid Res. 56, 51-59.

Kim, W., Zandoná, M.E., Kim, S.H., and Kim, H.J. (2015). Oral disease-modifying therapies for multiple sclerosis. J. Clin. Neurol. 11, 9-19.

Köster, A., Chao, Y.B., Mosior, M., Ford, A., Gonzalez-DeWhitt, P.A., Hale, J.E., Li, D., Qiu, Y., Fraser, C.C., Yang, D.D., et al. (2005). Transgenic angiopoietin-like (angptl)4 overexpression and targeted disruption of angptl4 and angptl3: regulation of triglyceride metabolism. Endocrinology 146, 4943-4950.

Labbé, S.M., Caron, A., Lanfray, D., Monge-Rofarello, B., Bartness, T.J., and Richard, D. (2015). Hypothalamic control of brown adipose tissue thermogenesis. Front. Syst. Neurosci. 9, 150.

Lee, M.J., Thangada, S., Claffey, K.P., Ancellin, N., Liu, C.H., Kluk, M., Volpi, M., Sha'afi, R.I., and Hla, T. (1999). Vascular endothelial cell adherens junction assembly and morphogenesis induced by sphingosine-1-phosphate. Cell 99, 301-312.

Lee, Y., Willers, C., Kunji, E.R., and Crichton, P.G. (2015). Uncoupling protein 1 binds one nucleotide per monomer and is stabilized by tightly bound cardiolipin. Proc. Natl. Acad. Sci. USA 112, 6973-6978.

Liu, Y., Wada, R., Yamashita, T., Mi, Y., Deng, C.X., Hobson, J.P., Rosenfeldt, H.M., Nava, V.E., Chae, S.S., Lee, M.J., et al. (2000). Edg-1, the G proteincoupled receptor for sphingosine-1-phosphate, is essential for vascular maturation. J. Clin. Invest. 106, 951-961.

Lowell, B.B., and Flier, J.S. (1997). Brown adipose tissue, beta 3-adrenergic receptors, and obesity. Annu. Rev. Med. 48, 307-316.

Mandala, S., Hajdu, R., Bergstrom, J., Quackenbush, E., Xie, J., Milligan, J., Thornton, R., Shei, G.J., Card, D., Keohane, C., et al. (2002). Alteration of lymphocyte trafficking by sphingosine-1-phosphate receptor agonists. Science 296, 346-349.

Moon, M.H., Jeong, J.K., Lee, J.H., Park, Y.G., Lee, Y.J., Seol, J.W., and Park, S.Y. (2012). Antiobesity activity of a sphingosine 1-phosphate analogue FTY720 observed in adipocytes and obese mouse model. Exp. Mol. Med. 44, 603-614.

Moon, H., Chon, J., Joo, J., Kim, D., In, J., Lee, H., Park, J., and Choi, J. (2013). FTY720 preserved islet $\beta$-cell mass by inhibiting apoptosis and increasing survival of $\beta$-cells in db/db mice. Diabetes Metab. Res. Rev. 29, 19-24.

Murata, N., Sato, K., Kon, J., Tomura, H., Yanagita, M., Kuwabara, A., Ui, M., and Okajima, F. (2000). Interaction of sphingosine 1-phosphate with plasma components, including lipoproteins, regulates the lipid receptor-mediated actions. Biochem. J. 352, 809-815.

Nofer, J.R., van der Giet, M., Tölle, M., Wolinska, I., von Wnuck Lipinski, K., Baba, H.A., Tietge, U.J., Gödecke, A., Ishii, I., Kleuser, B., et al. (2004). HDL induces NO-dependent vasorelaxation via the lysophospholipid receptor S1P3. J. Clin. Invest. 113, 569-581. 
Oo, M.L., Chang, S.H., Thangada, S., Wu, M.T., Rezaul, K., Blaho, V., Hwang, S.I., Han, D.K., and Hla, T. (2011). Engagement of S1P 1 -degradative mechanisms leads to vascular leak in mice. J. Clin. Invest. 121, 2290-2300.

Paik, J.H., Chae, Ss, Lee, M.J., Thangada, S., and Hla, T. (2001). Sphingosine 1-phosphate-induced endothelial cell migration requires the expression of EDG-1 and EDG-3 receptors and Rho-dependent activation of alpha vbeta3and beta1-containing integrins. J. Biol. Chem. 276, 11830-11837.

Pappu, R., Schwab, S.R., Cornelissen, I., Pereira, J.P., Regard, J.B., Xu, Y., Camerer, E., Zheng, Y.W., Huang, Y., Cyster, J.G., and Coughlin, S.R. (2007). Promotion of lymphocyte egress into blood and lymph by distinct sources of sphingosine-1-phosphate. Science 316, 295-298.

Peirce, V., and Vidal-Puig, A. (2013). Regulation of glucose homoeostasis by brown adipose tissue. Lancet Diabetes Endocrinol. 1, 353-360.

Penaranda, C., Tang, Q., Ruddle, N.H., and Bluestone, J.A. (2010). Prevention of diabetes by FTY720-mediated stabilization of peri-islet tertiary lymphoid organs. Diabetes 59, 1461-1468.

Poti, F., Bot, M., Costa, S., Bergonzini, V., Maines, L., Varga, G., Freise, H., Robenek, H., Simoni, M., and Nofer, J.R. (2012). Sphingosine kinase inhibition exerts both pro- and anti-atherogenic effects in low-density lipoprotein receptor-deficient (LDL-R(-/-)) mice. Thromb. Haemost. 107, 552-561.

Poti, F., Ceglarek, U., Burkhardt, R., Simoni, M., and Nofer, J.R. (2015). SKI-II-a sphingosine kinase 1 inhibitor-exacerbates atherosclerosis in low-density lipoprotein receptor-deficient (LDL-R-/-) mice on high cholesterol diet. Atherosclerosis 240, 212-215.

Prager, B., Spampinato, S.F., and Ransohoff, R.M. (2015). Sphingosine 1-phosphate signaling at the blood-brain barrier. Trends Mol. Med. 21, 354-363.
Shen, Y., Lookene, A., Nilsson, S., and Olivecrona, G. (2002). Functional analyses of human apolipoprotein $\mathrm{Cll}$ by site-directed mutagenesis: identification of residues important for activation of lipoprotein lipase. J. Biol. Chem. 277, 4334-4342.

Speakman, J.R., Fletcher, Q., and Vaanholt, L. (2013). The '39 steps': an algorithm for performing statistical analysis of data on energy intake and expenditure. Dis. Model. Mech. 6, 293-301.

Stone, M.L., Sharma, A.K., Zhao, Y., Charles, E.J., Huerter, M.E., Johnston, W.F., Kron, I.L., Lynch, K.R., and Laubach, V.E. (2015). Sphingosine-1-phosphate receptor 1 agonism attenuates lung ischemia-reperfusion injury. Am. J. Physiol. Lung Cell. Mol. Physiol. 308, L1245-L1252.

Vallerand, A.L., Lupien, J., and Bukowiecki, L.J. (1986). Cold exposure reverses the diabetogenic effects of high-fat feeding. Diabetes 35, 329-334.

van Marken Lichtenbelt, W.D., Vanhommerig, J.W., Smulders, N.M. Drossaerts, J.M., Kemerink, G.J., Bouvy, N.D., Schrauwen, P., and Teule, G.J. (2009). Cold-activated brown adipose tissue in healthy men. N. Engl. J. Med. 360, 1500-1508.

Williams, K.J., and Fisher, E.A. (2011). Globular warming: how fat gets to the furnace. Nat. Med. 17, 157-159.

Wu, C., Cheng, W., Xing, H., Dang, Y., Li, F., and Zhu, Z. (2011). Brown adipose tissue can be activated or inhibited within an hour before 18F-FDG injection: a preliminary study with microPET. J. Biomed. Biotechnol. 2011, 159834.

Xu, N., and Dahlbäck, B. (1999). A novel human apolipoprotein (apoM). J. Biol. Chem. 274, 31286-31290. 